San Jose State University

SJSU ScholarWorks

Master's Theses

Master's Theses and Graduate Research

Fall 2018

\title{
Application of Model Predictive Control in Modular Multilevel Converter for MTPA Operation and SOC Balancing
}

Mohit Sharma

San Jose State University

Follow this and additional works at: https://scholarworks.sjsu.edu/etd_theses

\section{Recommended Citation}

Sharma, Mohit, "Application of Model Predictive Control in Modular Multilevel Converter for MTPA Operation and SOC Balancing" (2018). Master's Theses. 4983.

DOI: https://doi.org/10.31979/etd.54wv-z423

https://scholarworks.sjsu.edu/etd_theses/4983

This Thesis is brought to you for free and open access by the Master's Theses and Graduate Research at SJSU ScholarWorks. It has been accepted for inclusion in Master's Theses by an authorized administrator of SJSU ScholarWorks. For more information, please contact scholarworks@sjsu.edu. 


\author{
A Thesis \\ Presented to
}

The Faculty of the Department of Electrical Engineering

San José State University

\author{
In Partial Fulfillment \\ of the Requirements of the Degree \\ Master of Science
}

by

Mohit Sharma

December 2018 
(C) 2018

Mohit Sharma

ALL RIGHTS RESERVED 
The Designated Thesis Committee Approves the Thesis Titled

APPLICATION OF MODEL PREDICTIVE CONTROL IN MODULAR MULTILEVEL CONVERTER FOR MTPA OPERATION AND SOC BALANCING

by

Mohit Sharma

APPROVED FOR THE DEPARTMENT OF ELECTRICAL ENGINEERING

SAN JOSÉ STATE UNIVERSITY

December 2018

Mohamed Badawy, Ph.D.

Birsen Sirkeci, Ph.D.

Saeid Bashash, PhD
Department of Electrical Engineering

Department of Electrical Engineering

Department of Mechanical Engineering 


\section{ABSTRACT \\ APPLICATION OF MODEL PREDICTIVE CONTROL IN MODULAR MULTILEVEL CONVERTER FOR MTPA OPERATION AND SOC BALANCING \\ by Mohit Sharma}

In this thesis, a one-step horizon model predictive control strategy (MPC) is implemented in a multilevel modular converter (MMC) to control the speed of an electric vehicle (EV) motor. Maximum torque per ampere (MTPA) and field weakening (FW) control strategies are used to generate reference signals for maximum torque output. The proposed control scheme aims to track the reference signal by independently regulating voltages from the MMC modules. To achieve this, the switches of the MMCs are directly controlled, eliminating the need for a pulse width modulator. A one-step horizon implementation of MPC ensures the robustness of the control system by making the real-time implementation possible. It leads to favorable performance under asymmetrical loads. The phase voltage is supplied to the motor through the MMC architecture which is composed of a large number of battery cells connected in series to supply the motor drive. Due to the non-identical characteristics of the battery, the state of charge (SOC) and the terminal voltage of the cells vary significantly at different operating conditions. The given control scheme is also incorporating a voltage balancing property that ensures the terminal voltages of all the battery cells in the MMC architecture are equalized. Finally, simulation results are presented to show the effectiveness of this control strategy and hardware is under development to validate the system performance. 


\section{TABLE OF CONTENTS}

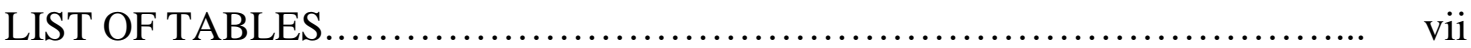

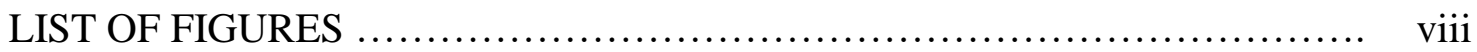

LIST OF ABBREVIATIONS ............................................ $\quad$ x

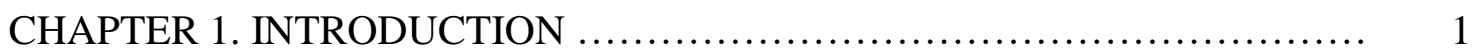

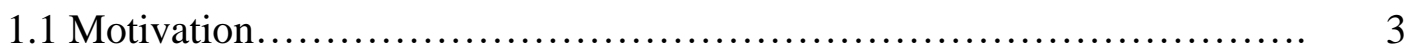

1.2 Thesis Organization.............................................. 4

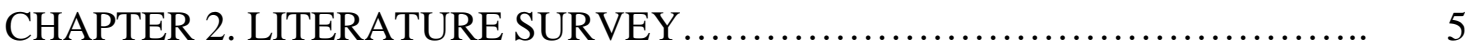

2.1 Available Control Strategies.......................................... 6

2.2 MMC Power Converter.............................................. 8

CHAPTER 3. CONTROL STRUCTURE.................................. 13

3.1 Topology of the MMC ............................................... 13

3.1.1 Switching of MMCs......................................... 14

3.2 Drive Model..................................................... 15

3.3 Proposed Control Scheme......................................... 17

3.4 Control Strategy................................................ 18

3.4.1 Reference Generation by MTPA and FW Algorithm............... 18

3.4.2 Cost Function................................................. 22

3.4.3 Predictive Model............................................... 24

3.5 State of Charge Balancing ........................................ 26

3.5.1 Algorithm................................................ 26

CHAPTER 4. VALIDATION OF RESULTS ............................... 28

4.1 UDDS Tracking................................................. 28

4.2 Effect of Weighting Factor on System Performance...................... 29

4.3 Effect of Number of Modules on System Performance .................... $\quad 30$

4.4 Effect of Sampling Frequency on System Performance .................. 31

4.5 MTPA Tracking.................................................... 33

4.6 Switching Loss................................................. 34

4.6.1 Effect of Number of Modules................................. 35

4.6.2 Effect of Sampling Frequency ............................... 36

4.6.3 Effect of the Cost Function................................. 37

4.7 Effect of Cost Function on Voltage Waveform and THD............... 38

CHAPTER 5. HARDWARE IMPLEMENTATION......................... 39

5.1 Design of MMC Sub-Module................................... 39

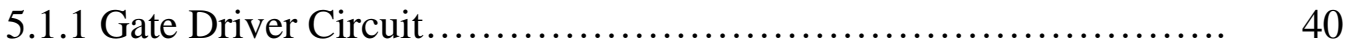

5.1.2 Buffer for Gate Signals.................................... 41 
5.1 .3 Sensors...................................................... 41

5.1.4 Protection Circuits........................................... 44

CHAPTER 6. CONCLUSION AND FUTURE WORK.......................... 46

6.1 Conclusion.......................................................... 46

6.2 Future Work...................................................... 47

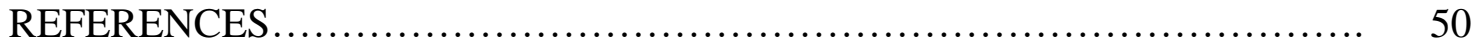




\section{LIST OF TABLES}

Table 3-1 Switching Sequence of H-Bridge in Figure 3-2.............. 15

Table 4-1 Motor Parameters........................................ 28 


\section{LIST OF FIGURES}

Figure 1-1 EVs vs. ICE powered vehicles............................. 1

Figure 1-2 Market share (in \%) of global EV and PHEV sales .............. 2

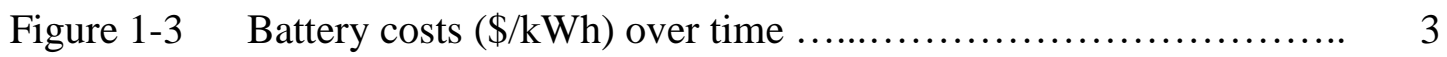

Figure 2-1 MMC conceptual realization............................. 9

Figure 2-2 Voltage waveform in the two-level VSC and MMC ............ 10

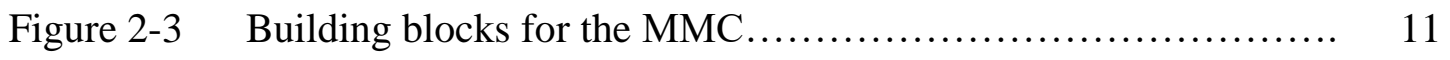

Figure 3-1 Three-phase MMC with n modules per phase.................. 14

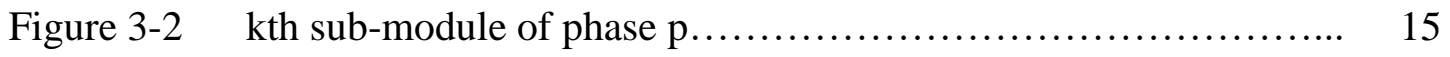

Figure 3-3 IPMM fed by three-phase MMCs .......................... 16

Figure 3-4 Predictive current control scheme for IPMM .................. 19

Figure 3-5 (a) Speed of motor. (b) MTPA, MTPV and FW

trajectories........................................... 21

Figure 4-1 Speed tracking: (a) UDDS drive cycle tracking, (b) Speed

tracking error........................................... 29

Figure 4-2 For $\lambda_{1}=1, \lambda_{2}=0.001, \lambda_{3}=0$; (a) three-phase voltage. (b) threephase current. (c) torque ripple. (d) error between reference and actual speed..................................................

Figure 4-3 For $\lambda_{1}=0.8, \lambda_{2}=0.007, \lambda_{3}=0$; (a) three phase voltage. (b) three phase current. (c) torque ripple. (d) error between reference and actual speed

Figure 4-4 Number of sub-modules: five (first row); fifty (second row); one hundred (third row); phase voltages (a), (d), (g). current tracking error (b), (e), (h). torque ripple (c), (f), (i) .....................

Figure 4-5 Effect of sampling frequency sub-modules in MMCs (five per phase): (a) phase voltages at $5 \mathrm{KHz}$, (b) error in reference tracking at $5 \mathrm{KHz}$, (c) phase voltages at $50 \mathrm{KHz}$, (d) error in reference tracking at $50 \mathrm{KHz}$. 
Figure 4-6 Effect of sampling frequency on MMC output (a) three-phase voltages at $5 \mathrm{KHz},(\mathrm{b})$ error in reference tracking at $5 \mathrm{KHz}$, (c) phase voltages at $50 \mathrm{KHz}$, (d) error in reference tracking at $50 \mathrm{KHz}$.

Figure 4-7 MTPA tracking at maximum command torque: (a) speed tracking. (b) motor current. (c) electromechanical torque. (d) MTPA curve.

Figure 4-8 (a) Speed tracking error in 10 sub-modules (dashed) and 50 sub-modules (orange); (b) Normalized switching losses in 10 sub-modules and 50 sub-modules.

Figure 4-9 (a) Speed tracking error at $10 \mathrm{kHz}$ and $50 \mathrm{kHz}$ sampling frequency.

(b) normalized switching losses at $10 \mathrm{kHz}$ sampling frequency and $50 \mathrm{kHz}$ sampling frequency.

Figure 4-10 (a) Reference speed. (b) Switching losses variation with cost function....

Figure 4-11 (a) Rate of change of voltage states at the output of MMC. (b) variation of THD with cost function. (c) voltage waveform for $\lambda_{1}=0.8, \lambda_{2}=0.007, \lambda_{3}=0.05$. (d) voltage waveform for $\lambda_{1}=1$, $\lambda_{2}=0, \lambda_{3}=0$.

Figure 5-1 Schematics of buffer and gate driver circuit.

Figure 5-2 Schematics of the current sensor circuit......................

Figure 5-3 Schematics of voltage sensor.

Figure 5-4 Schematics of overload protection circuit

Figure 6-1 Schematics of new sub-module topology 


\section{LIST OF ABBREVIATIONS}

ICE - Internal Combustion Engine

PHEVs - Plug-in Hybrid EVs

IPMSM - Interior permanent magnet synchronous machine

IM - Induction motor

BLDCM - Brushless DC motor

SRM - Switch reluctance motor

IPMM - Interior permanent magnet motor

SISO - Single input single output

MIMO - Multiple input multiple output

VSC - Voltage source converter

PWM - Pulse width modulation

MPC - Model Predictive Control

MTPA- Maximum Torque Per Ampere

MTPV - Maximum Torque Per Volt

FW- Field Weakening

SOC - State of charge

MMC - Modular Multilevel Converter

PWM - Pulse width modulation

VSC - Voltage source converter

IPMM - Interior permanent magnet machine

UDDS - Urban dynamometer driving schedule 
THD - Total harmonic distortion 


\section{CHAPTER 1. INTRODUCTION}

The need for automobiles for personal use and public transportation has increased over time alongside the rise in the standard of living. The automobile market of 2018 offers more buying options than ever in terms of size, style, luxury levels, and performance. Thus, classic standard gas and diesel-powered vehicles are no longer the only options for consumers who are choosing an automobile in the marketplace.

Electrically powered vehicles are now more prevalent than they were few years ago. These cars are better for the environment, and the electric vehicles (EVs) of 2018 are superior to an internal combustion engine (ICE) powered vehicles in terms of annual maintenance and fuel costs [see [1],[2], Figure 1-1].

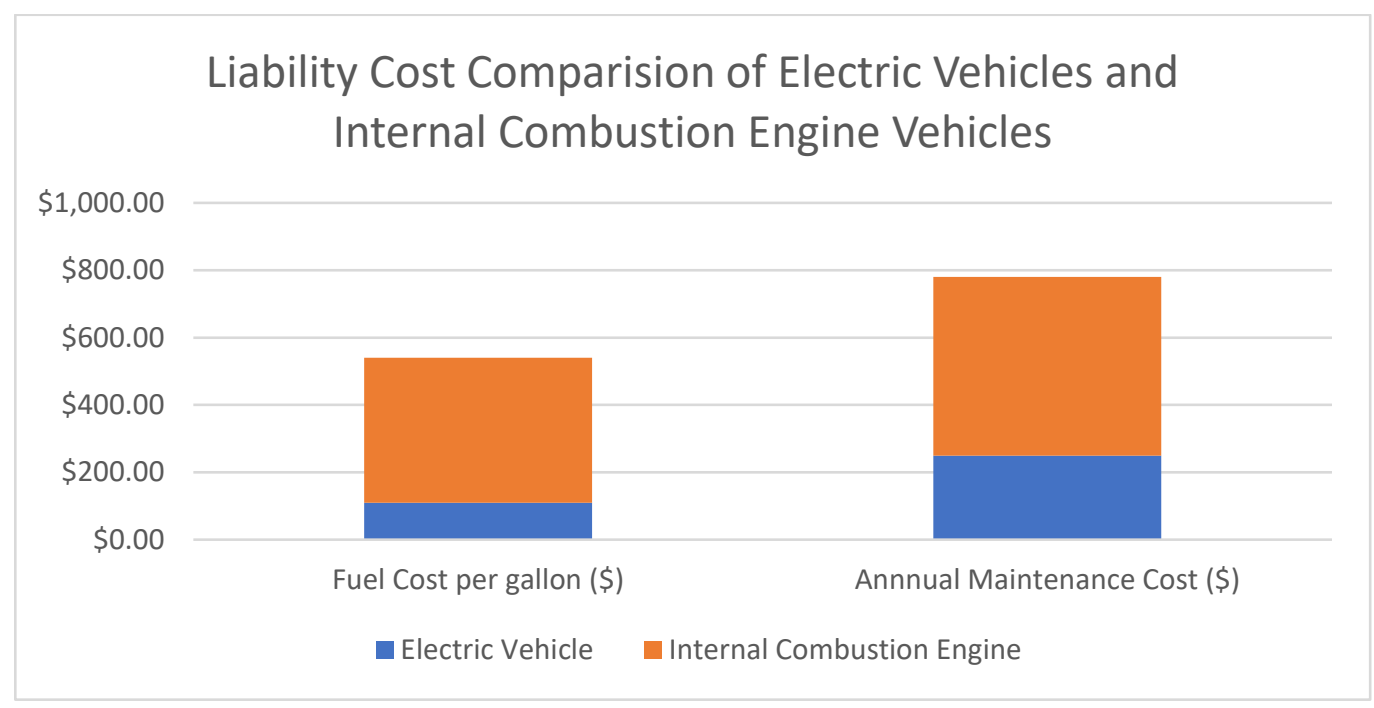

Figure 1-1 EVs vs. ICE powered vehicles.

The market share of EVs has been on the rise for the past few years. Figure 1-2 depicts the global share of battery-EVs (BEVs) and plug-in hybrid EVs (PHEVs) as a proportion of the total vehicle sales. Macquarie's analysis of official sales data from China, the US, Europe, Japan, and Canada has indicated that EVs accounted for 1.7\% of 
new car sales in those markets, which represents a $1.1 \%$ increase from 2016 as shown in [3, Figure 1-2].

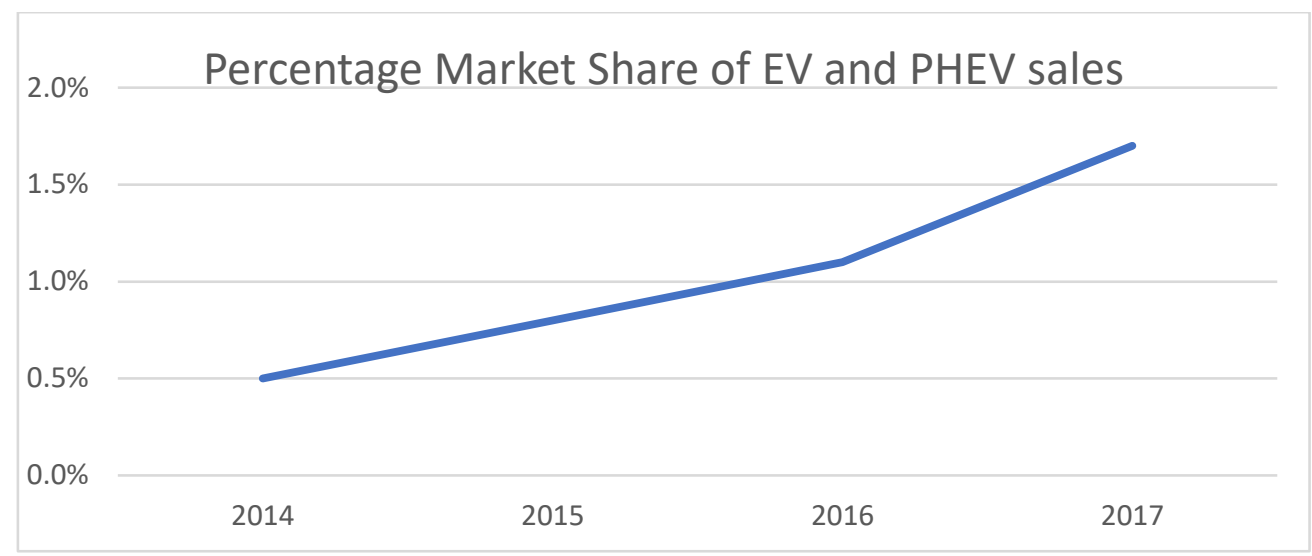

Figure 1-2 Market share (in \%) of global EV and PHEV sales.

The EV industry faces a number of challenges, including high costs, the lack of enough charging stations, and relatively short driving range. To improve the range, EV manufacturers invested in expensive battery technology to increase the charge-holding capacity. This investment further increased the cost of the vehicles.

In 2018, EVs are still more expensive than ICE vehicles, but this difference may change in the next decade as battery costs continue to decline rapidly. According to [3], between 2014 and 2016, the cost of an electric battery decreased over $50 \%$ as a result of process improvements and scale effects. This reduction has contributed to greater parity in costs between EVs and ICE vehicles [4, Figure 1-3]. 


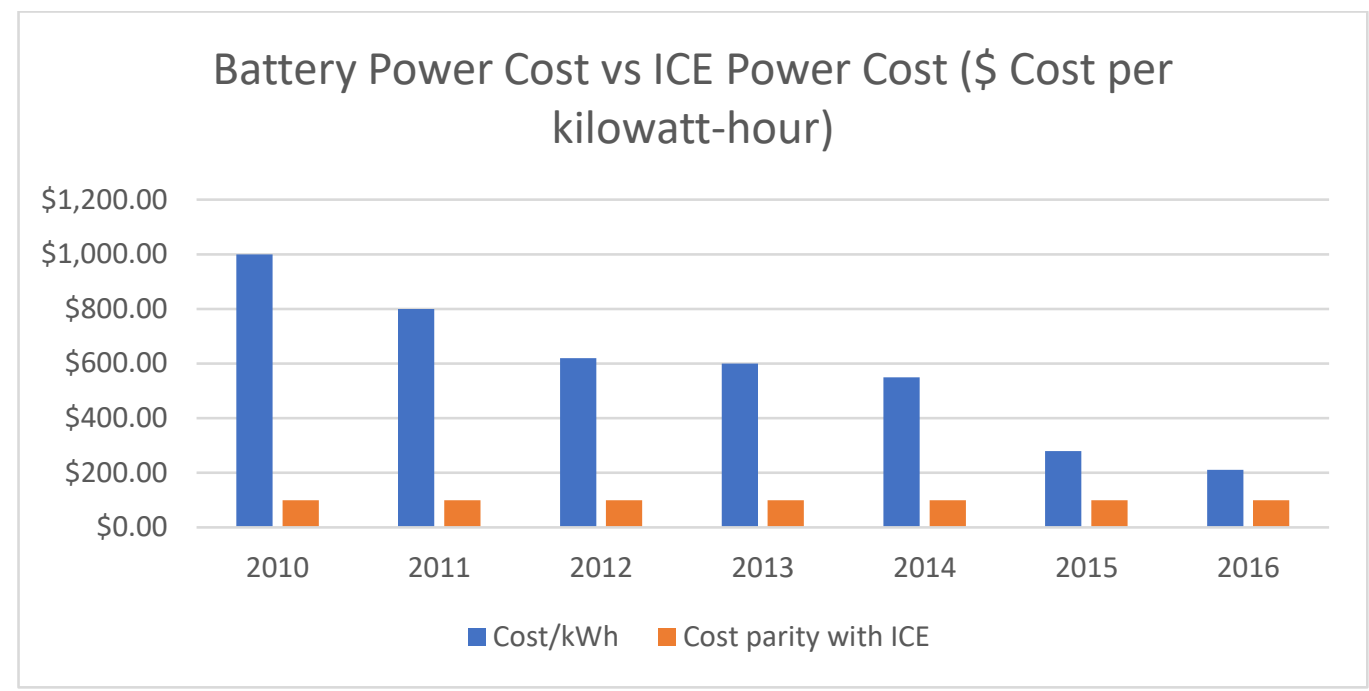

Figure 1-3 Battery costs $(\$ / \mathrm{kWh})$ over time.

Besides the cost, another key aspect of EVs is their performance in comparison to ICE vehicles. The performance depends on numerous factors, such as the type of the electric motor, the control strategy, the power electronics converter in the system to supply power, and the battery management strategies for optimal performance.

Extensive work has addressed the control structures developed to improve the motor operation efficiency. Aspects of motor drive that can improve the performance include the appropriate selection of a motor and a power converter topology and the development of an efficient and robust control strategy. Chapter 2 of this thesis presents a literature survey regarding types of motor control and various power converter topologies.

\subsection{Motivation}

The thesis aims to devise a MPC technique that allows an EV motor to run at MTPA while managing the energy of the individual battery cells for optimal performance. Various types of electric motors can be used for the chosen application such as an interior permanent magnet synchronous motor (IPMSM), an induction motor (IM), a brushless 
DC motor (BLDCM), and a switch reluctance motor (SRM). Because of characteristics such as high-power density, substantial efficiency and reliability, low torque ripple, and a wide range of speed regulation, the IPMSM is used for the work in this thesis [5]. A multilevel converter was also used to supply power to the IPMSM. Multilevel converters have attracted considerable attention for their high-power and high-voltage applications, as they provide superior power quality at the AC-side and can operate at higher voltage levels compared to conventional two-level converters. In comparison to the conventional converter, MMCs switch at a lower voltage and thus have reduced switching losses. Because of the modular nature of the topology, MMCs provide control of individual battery cells, which facilitates the implementation of the battery management of each cell.

\subsection{Thesis Organization}

This thesis first reviews the relevant literature to identify existing control strategies for controlling electric motors. Chapter 2 presents various topologies of MMCs and applications of MPC. Subsequently, Chapter 3 discusses the proposed control structure and the problem statement of the thesis. Chapter 4 contains validation of the proposed control strategy in the form of simulation results, and Chapter 5 addresses the hardware development of MMCs. Finally, Chapter 6 recommends future actions with respect to the proposed strategy. 


\section{CHAPTER 2. LITERATURE SURVEY}

A modern electric drive is composed of three major subsystems. The first is the electric propulsion subsystem, which consists of a vehicle controller, an electronic power converter, an electric motor, a manual transmission, and driving wheels. The second, namely the power supply subsystem, includes a power supply, a power management unit, and a unit energy recharge. The third is the auxiliary subsystem, which involves drive power steering, a climate control room, and an auxiliary power unit [5]. This thesis focuses on the electric propulsion subsystem and specifically considers the electric motor, power converter, and vehicle controller. As the introduction has indicated, a variety of electric motors can serve electronic vehicle applications such as an IPMSM, IM, BLDC, SR. Of these motors, the IPMSM is the chosen motor for this thesis due to its superiority in terms of high-power density, high-efficiency, good reliability, low torque ripple, and a wide range of speed regulation. In [6], the authors compared the field-weakening (FW) performance of synchronous reluctance and interior permanent magnet motor (IPMM) against that of a baseline $2.2 \mathrm{~kW}$ induction machine under rated load and overload conditions. They found that the performance of the synchronous reluctance machine was comparable to that of the induction machine. On the other hand, the IPMMs offered significantly better output power above rated speed compared to the other two machines. The multiple-barrier IPMM design exhibited the most promising FW performance. 


\subsection{Available Control Strategies}

The current literature provides numerous control strategies for electric motors. The preferred concepts in industrial applications are linear control combined with modulation schemes and nonlinear control based on hysteresis bounds [7]. With the advent of powerful digital hardware (digital signal processor (DSP) and microprocessor), more complex concepts have been realized, such as fuzzy [8], adaptive [9], and predictive control [10].

However, for large drive systems, the linear control with modulation scheme leads to poor control performance, as the dynamics must be scaled with respect to the sampling frequency. To improve the robustness and stability, the bandwidth should be set 5 to 10 times below the sampling frequency. Previous research has investigated predictive control approaches to enhance the dynamic performance [see 11].

Another control algorithm that has gained popularity in the field of power electronics is MPC. Although it was introduced in the 1960s, MPC found its industrial applications in the 1970s. Compared to the classical control, it is more calculation intensive, and it was therefore first used in the chemical processing industry, where the time constant of processes is sizeable to perform the mathematical calculations [11, pp. 1-2]. From the 1980s, MPC was employed for low switching power electronics applications due to a lack of high-speed processors, such as DSPs and field-programmable gate arrays (FPGAs). However, with the introduction of high-speed processors, MPC has found high-frequency applications, such as in AC drives. 
MPC predicts the future system states in discrete time using a system model. In every sample time, a constant number of future states are predicted, which is called the prediction horizon, $\mathrm{N}$ [12]. In power electronics, the sampling periods are usually small, thereby restricting $\mathrm{N}$ to a few sampling periods. The outcomes of the prediction are evaluated by a cost function (also known as a quality or decision function) [11], which provides the criterion for choosing the right control action. Because of the cost function, MPC can handle non-linear systems, multiple input and multiple output (MIMO) systems, and system constraints in a uniquely unified way.

Application of MPC in electrical drives is of particular interest for two reasons. First, accurate linear models of electrical drives can be obtained by analytical methods and identification techniques. Second, bounds on drive variables, such as the maximum phase current and phase voltage, are significant for the dynamics of the system. It is difficult to set up constraints on the states in conventional state space controllers. The two main approaches to manage system constraints are the conventional anti-windup techniques of PI controllers and MPC [13].

Despite the advantages mentioned above, only a few research laboratories have applied MPC to electrical drives. In [14], a long-range MPC was applied to an IM for only current regulation. In [15], a model-based predictive control of rotor flux and speed of a vector-controlled IM was presented. In [16], MPC was used as a current or a torque-flux controller to directly drive the inverter states. A comprehensive description of the design process of an MPC controller for an electric drive is available in [13]. The 
explanation stresses on the ability of MPC to systematically cope with hard constraints on inputs and states and its suitability for directly addressing multivariable systems.

A novel type of model-predictive direct torque control (MP-DTC) has been proposed in [17], which used a discrete-time model of the machine and power converter to predict a finite set of voltage vectors. The cost function is designed to meet multiple demands, such as torque reference tracking, MTPA tracking for high electrical efficiency, and limitation of the states to their largest acceptable values. The authors have extended their work in [16] by implementing an FW operation in their novel type MP-DTC [18]. They designed a controller to track the MTPA trajectory when the motor speed is below the rated speed and to operate in the FW region whenever the speed is above the rated speed. In addition, the authors of [17] have developed a cost function that is suitable for operation at high speeds without penalizing operations below the rated speed.

\subsection{Power Converter}

All of the above controllers use a two-level voltage source inverter (2L-VSI), as it is one of the most general converter topologies in the industry. However, for high-power applications, multilevel converters have attracted significant attention and are becoming one of the top clean power and energy-conversion options for new topologies and control in both the industry and academia. The authors of [19] have performed a survey of various topologies of multilevel inverters.

Multilevel converter topologies first emerged in the late-1960s with the introduction of a voltage-source converter (VSC) named the H-bridge converter [20]. The problems with VSCs include lack of modularity, failure management, reliability, and simple, 
structure-based design. The solution to these problems was a modular-based multilevel converter, which offered a myriad of benefits, such as modularity, simple voltage scaling by a series connection of cells, low total harmonic distortion (THD), and a filterless configuration for standard machines or grid converters [21],[22]. Nevertheless, this topology also presents disadvantages, the most notable of which are the presence of more switching devices compared to conventional converters and the existence of a relatively high circulating current due to the intrinsic features of MMCs during operation.

The topology of MMCs derives from the two-level VSC, which features two switches at the top and bottom on each arm of the converter. To achieve the desired harmonic content, a high switching frequency of the two-level voltage converter is sustained. The high switching frequency of the converter MOSFETs in medium and high-power applications leads to high switching losses. Therefore, there was a need for a topology that provides low harmonic content at low switching frequency. The development of the MMC concept from the two-level converter is depicted in [23, Figure 2-1].

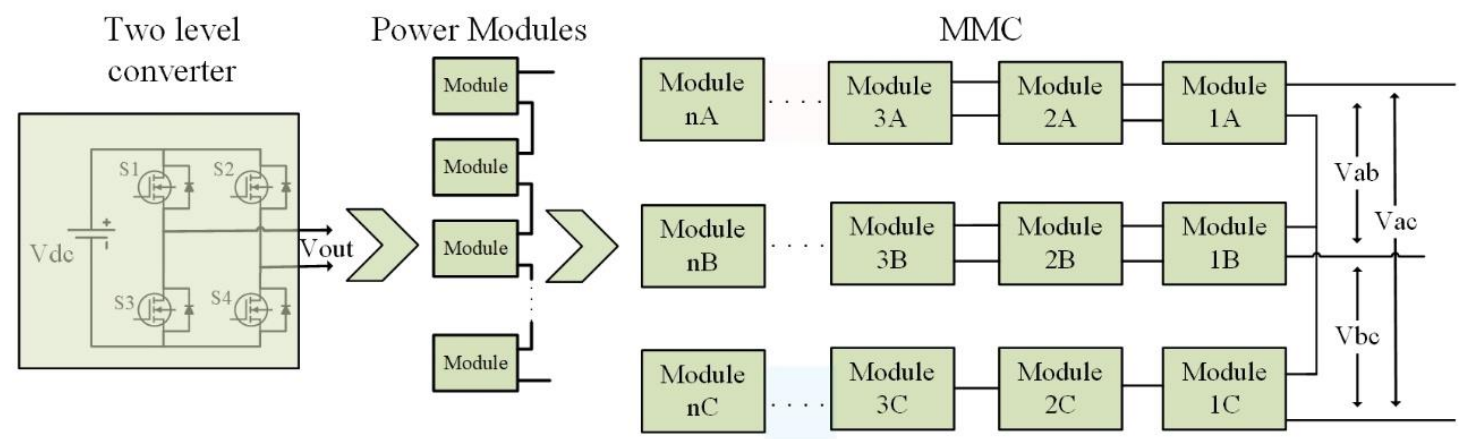

Figure 2-1 MMC conceptual realization. 
The MMC topology can be formed by replacing the series of connected switches in a two-level converter with a series of single-phase two-level converter sub-modules, where the half-bridge converter can typically realize each sub-module [22].

Employing a series of connected half-bridge cells can significantly reduce the switching frequency that is associated with the converter [24]. The single-phase voltage waveform in the two-level converter versus the voltage waveform in the realized MMC is illustrated in [23, Figure 2-2].

2- Level VSC

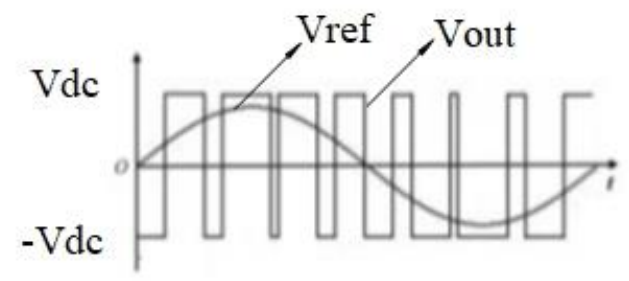

$\mathrm{MMC}$

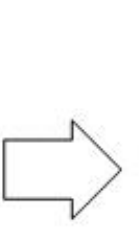

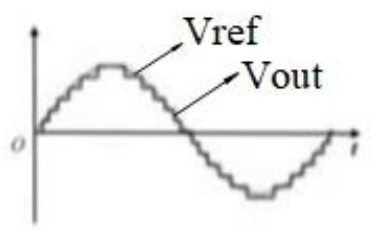

Figure 2-2 Voltage waveform in the two-level VSC and MMC.

Various topologies of MMC are formed according to certain circuit topologies of sub-modules in the MMC architecture. As [23, Figure 2-3] indicates, each sub-module can be a half bridge, full bridge, or series of switches.

The half-bridge sub-modules can generate only positive voltages, while the fullbridge modules are able to produce negative voltages as well (see Figure 2-3). 


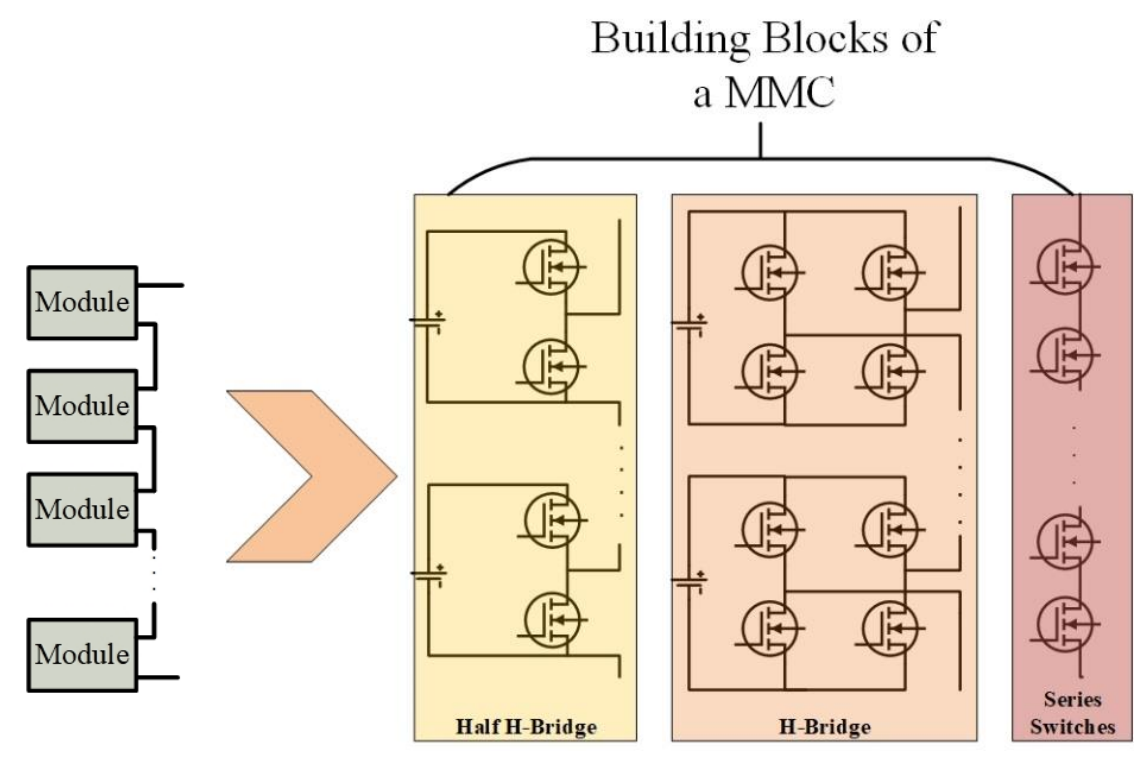

Figure 2-3 Building blocks for the MMC.

The MMC with a half bridge as a sub-module provides a solution for the power losses due to high switching frequency in the two-level converter at the cost of having double the number of switches and a massive amount of capacitance. The main disadvantage of this topology is its inability to block the current path during the DC fault [22]. In contrast, the full-bridge MMC topology permits the ride-through ability of the configuration and suppression of the DC faults. However, it requires twice as many MOSFETs as half bridge does. Various converter topologies that combine the features and advantages of both the MMC and two-level converters have been highlighted in [25].

The MMC is a MIMO system. However, its switching is controlled by schemes that were intended for single-input-single-output systems (SISO). Multiple PI control loops with carrier-based pulse width modulation (PWM) are used to control an MMC. The large number of sub-modules makes it difficult to tune all of the PI loops. MPC is suitable for controlling MIMO systems [26]. Since MPC has a simple design, is easy to 
model, and can incorporate system constraints, it has become increasingly popular for controlling MMCs [27].

In EVs, conventional energy-storage systems consist of battery cells that are connected in series and charged and discharged by the same current. Because of their varying electrochemical characteristics, each cell will have a different terminal voltage. However, because of this difference, the charge and discharge of cells must be stopped, even if one of the cells reaches its cut-off voltage. Thus, battery cell screening must be performed to ensure equal terminal voltage or state of charge (SOC) of the cells [28].

In [29], the cascaded H-bridge converters were used to balance the voltage of the battery cells. Each H-bridge cell controlled one battery cell. The voltage balance of the cells could be achieved by separately controlling the charging and discharging. The output voltage of the converter was multilevel, which resembles one of the topologies of aforementioned MMCs. This thesis focuses on the MPC strategy that cascaded H-bridge converters apply to control the speed of IPMMs. The next chapter elaborates on the control strategy. 


\section{CHAPTER 3. CONTROL STRUCTURE}

Chapter 2 has discussed various MMC topologies that exist in the literature as well as the benefits of using MPC to control the output of MMC. This chapter presents a one-step horizon MPC strategy that the MMC implements to track the reference current and, hence, control the speed of an IPMM motor. To obtain the maximum energy efficiency, MTPA, maximum torque per volt (MTPV), and FW, control strategies are employed to generate reference signals. The proposed control scheme aims to track the reference signal that is generated by the MTPA, MTPV, and FW algorithm by independently regulating voltages from the MMC modules. The controller directly controls the switching of MOSFETs in the MMC sub-modules, thereby eliminating the need for a PWM wave.

The most significant advantage of MPC is the long prediction horizon range. However, short horizon prediction is less calculation intensive, and its implementation ensures robustness of the control system by allowing for its real-time implementation. The given MPC algorithm also incorporates a voltage-balancing property, which the chapter later discusses.

\subsection{Topology of the MMC}

Figure 3-1 presents the proposed MMC topology with $\mathrm{n}$ number of sub-modules. It resembles the hybrid cascaded multilevel converter topology in [30]. The MMC sub-module consists of a battery and H-bridge. This topology removes the need for a separate H-bridge, which was required to alternate the direction of the DC voltage in sub-modules with half-bridge inverters [30]. 


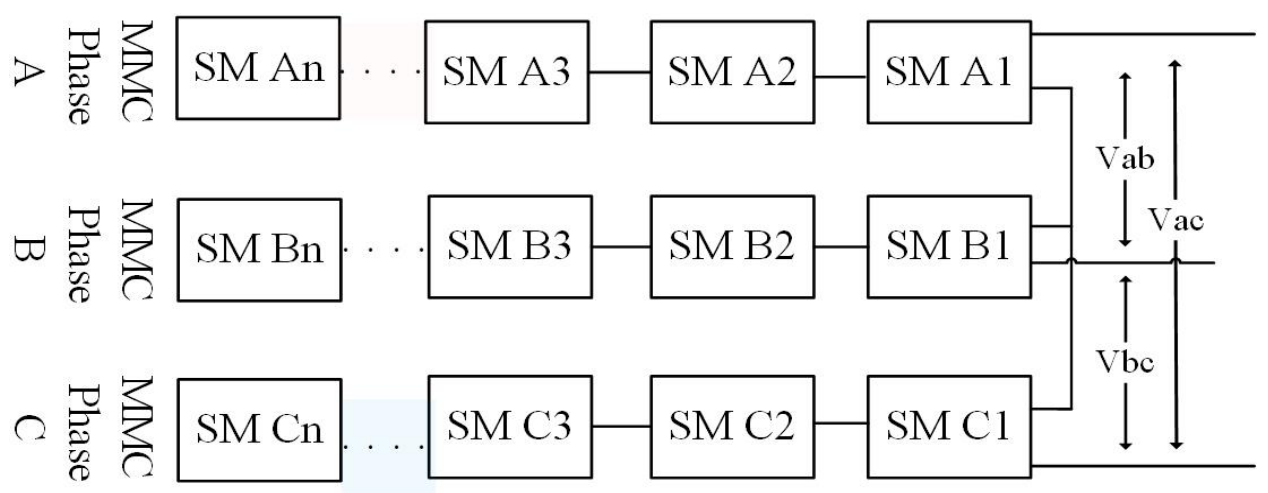

Figure 3-1 Three-phase MMC with n modules per phase.

Since MMCs are used to produce sinusoidal phase voltage for the IPMM, the individual control of sub-modules aids in creating a staircase-shaped sinusoidal voltage waveform at the output. The number of voltage levels depends on the number of sub-modules. If the number of sub-modules per phase is $n$, then the total voltage levels possible are $2 n+1$ per phase. The increase in the number of voltage levels at the output yields an output voltage that is closer to the sinusoidal waveform and therefore eliminates the need for any passive filtering elements. Thus, the rate of change of the applied voltage $(d v / d t)$ across the switching devices is reduced. Additionally, the harmonics content in the AC output voltage signal is lowered. These features render this topology suitable for energy storage systems in EVs [30].

\subsubsection{Switching of MMCs.}

The switching of an MMC that consists of $n$ sub-modules can be expressed in terms of a switch matrix. The switch matrix is given by $S W_{\text {matrix }}$ as follows:

$$
S W_{\text {matrix }}=\left[\begin{array}{lllllll}
S_{p 11} & S_{p 21} & . . & . . & . . & S_{p(n-1) 1} & S_{p n 1} \\
S_{p 12} & S_{p 22} & . . & . . & . . & S_{p(n-1) 2} & S_{p n 2} \\
S_{p 13} & S_{p 23} & . . & . . & . . & S_{p(n-1) 3} & S_{p n 3} \\
S_{p 14} & S_{p 24} & . . & . . & . . & S_{p(n-1) 4} & S_{p n 4}
\end{array}\right]_{4 x n}
$$


Four elements of each column in the switch matrix correspond to four switches in a sub-module (see Figure 3-2). $S_{p i j}$ represents the on or off state of each switch in the form of 0 (off) and 1 (on). Here, $p, i, j$ correspond to the MMC phase, sub-module number, and switch number, respectively. After each sample time $T_{s}$, the updated switch matrix is implemented through gate drivers.
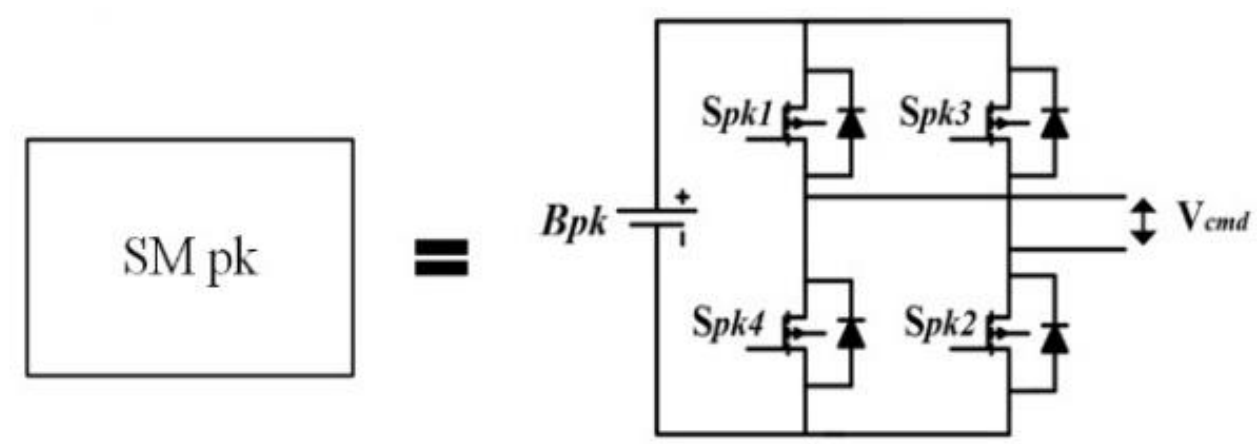

Figure 3-2 kth sub-module of phase p.

The sub-modules in MMCs consist of $\mathrm{H}$ bridges with a battery cell voltage of $V_{\text {cell }}$ (see Figure 3-2). Table 3.1 describes the switching of one H-bridge sub-module and its corresponding output voltage.

Table 3-1 Switching Sequence of H-Bridge in Figure 3-2

\begin{tabular}{|c|c|c|c|c|}
\hline Output Voltage & $S_{p k 1}$ & $S_{p k 2}$ & $S_{p k 3}$ & $S_{p k 4}$ \\
\hline$+V_{\text {cell }}$ & 1 & 1 & 0 & 0 \\
\hline$-V_{\text {cell }}$ & 0 & 0 & 1 & 1 \\
\hline 0 & 1 & 0 & 1 & 0 \\
\hline
\end{tabular}

\subsection{Drive Model}

This thesis considers an IPMM with three-phase stator windings. The machine is fed by three-phase MMCs (see Figure 3-3). 


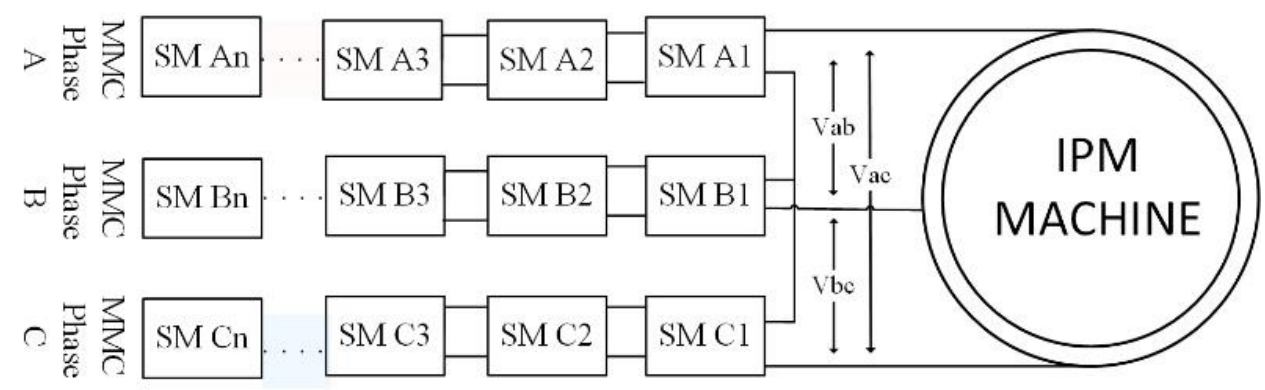

Figure 3-3 IPMM fed by three-phase MMCs.

In order to implement the MPC strategy in the IPMM and MMC systems, an accurate mathematical model of each is necessary. The mathematical model of IPMM is given in [31] as

$$
V(t)=L \frac{d i(t)}{d t}+R i(t)+e(t)
$$

Here, $\mathrm{V}(\mathrm{t})$ is the phase voltage, $i(t)$ is the phase current, $\mathrm{L}$ is the coil inductance, $\mathrm{R}$ is the resistance of the winding, and $e(t)$ is the back electromotive force (EMF) The rotor of the IPMMs have magnetic saliency, and the inductance measurement results change according to the rotor position (i.e. $L_{d} \neq L_{q}$ ). Effective inductance of the interior permanent magnet machine is given by $L_{I P M}[35]$ :

$$
L_{I P M}=\frac{3}{2}\left(\frac{\left(L_{q}+L_{d}\right)}{2}-\frac{L_{q}-L_{d}}{2} \cos 2 \theta\right)
$$

Here, $L_{d}$ and $L_{q}$ are motor $\mathrm{d}$ and $\mathrm{q}$ inductances, respectively, and $\theta$ is the rotor position. On rearranging and discretizing Equation 1, future values of load current, $i(k+1)$, can be predicted from voltages and measured currents at the $k t h$ sample [31]. The equation is 


$$
i(k+1)=i(k)\left(1-\frac{T_{S} R}{L_{I P M}}\right)+\frac{T_{S}}{L_{I P M}}(V(k)-e(k)) .
$$

The output voltage $V_{o}$ of the MMC in Figure 3-1 is a function of the switching matrix, $S W_{\text {matrix }}$, given by

$$
\begin{aligned}
& V_{o}=M . S W_{\text {matrix }} . \\
& \text { Here, } M=V_{\text {cell }}\left[\begin{array}{llll}
1 & 0 & -1 & 0
\end{array}\right] \text {. }
\end{aligned}
$$

Thus, Vo is given by

$$
\begin{gathered}
V_{o}=\left[\begin{array}{ccc}
V_{\text {module } 1} V_{\text {module2 }} & \ldots \ldots & V_{\text {module } n}
\end{array}\right] \\
V_{m m c}=\left|V_{o}\right|_{1} .
\end{gathered}
$$

At every sample instant, the switch matrix $S W_{\text {matrix }}$ is updated with one of the switch sequences (see Table 3.1) for each module (MOSFETs of H bridge) after MPC determines the voltage selection. The product of $S W_{\text {matrix }}$ and matrix M provides the voltage information of individual modules as given by Equation 6. Matrix multiplication of $\mathrm{M}$ with switch matrix yields the sub-module voltage matrix $V_{o}$ with dimension (1xn). The L1 norm of the vector $V_{o}$ represents the total voltage contribution of MMC in that phase.

\subsection{Proposed Control Scheme}

Figure 3-4 illustrates the proposed control system for reference speed tracking of an IPMM. It employs a model-based predictive speed control strategy to control the motor speed by tracking reference phase currents from each MMC. A discretized model of IPMM (described in Equation 3) can predict the future states of the motor. A cost function is designed to realize speed control and ensure that the input phase current always follows the MTPA trajectory when the motor speed is below the rated speed and follows the FW and MTPV trajectory when the speed is above the rated speed. The 
reference speed $\left(\omega_{\text {ref }}\right)$ is compared with the actual speed $\left(\omega_{\text {act }}\right)$ of the motor and used to generate commanded torque $\left(T_{c}\right)$. This commanded torque signal is converted to the reference current $\left(I_{r e f}\right)$ by MTPA and FW algorithms. Predictive control block predicts the future current and optimizes the cost function from $2 n+1$ available voltage level. After minimizing the cost function, the MPC algorithm selects the optimized voltage and generates the switch matrix. This switch matrix is fed to the to the MMCs, which then supply three-phase power to the interior permanent magnet machine. The predictive model also ensures voltage balancing of all the battery cells by tracking the cell voltages and sending the switching sequence accordingly.

\subsection{Control Strategy}

Figure 3-4 depicts the three main parts of the proposed control strategy:

(1) Generation of reference current Iref by MTPA and FW algorithms

(2) Cost function evaluation by prediction model

(3) Differential switching of sub-modules to ensure equal voltage distribution among the cells

\subsubsection{Reference Generation by MTPA and FW Algorithm.}

The reference current is generated by using the MTPA equations when the motor speed is below the rated speed. The motor cannot track the MTPA trajectory if the speed is above the rated speed. To obtain the maximum torque output, the motor must enter the FW region. 


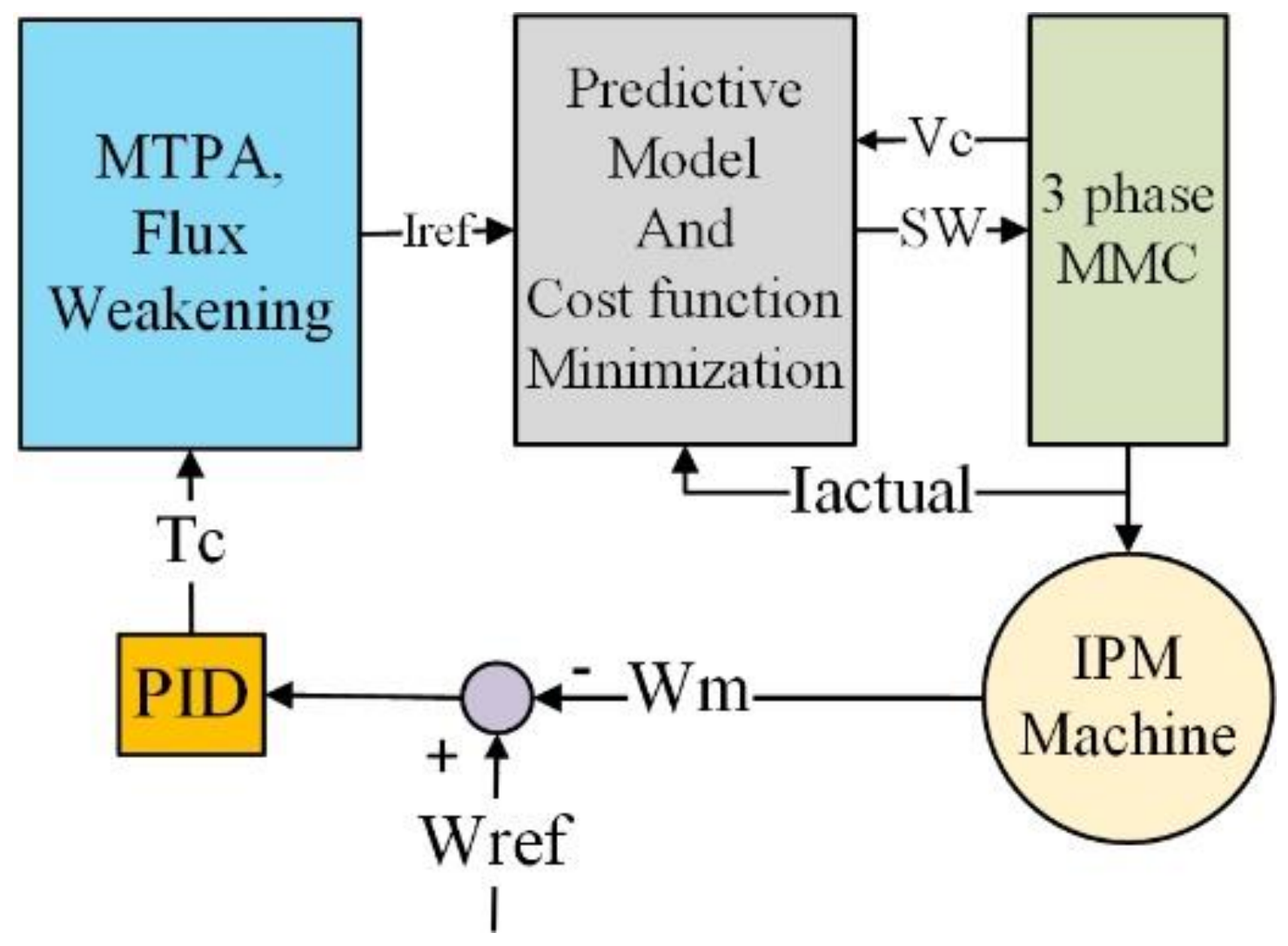

Figure 3-4 Predictive current control scheme for IPMM.

The well-known voltage and torque equations are given in [32-35]. They describe the electrical characteristics of an IPMM in d-q reference frame as follows:

$$
\begin{gathered}
=R i_{d}+L_{d} \frac{d}{d t} i_{d}-\omega L_{q} i_{q} \\
=R i_{q}+L_{q} \frac{d}{d t} i_{q}+\omega\left(L_{d} i_{d}+\lambda\right) \\
T_{e}=\frac{3}{2} \frac{P}{2}\left[\lambda_{m} i_{q}+\left(L_{d}-L_{q}\right)\left(i_{d} i_{q}\right)\right]
\end{gathered}
$$

Here, $V_{d}$ and $V_{q}, i_{d}$ and $i_{q}$ are the voltages and currents along the $\mathrm{d}$ and the qaxis, respectively. $T_{e}$ is the electrical torque, $L_{d}, L_{q}$ are the inductances along d-q axis, $\lambda_{m}$ is permanent magnet field strength, $\omega$ is the angular speed of the motor. 
Equation 10 reveals that non-identical $d q$ inductance values generate torque that increases alongside the magnitude of the $d$-axis current. Minimizing the total stator current helps to decrease the system conduction losses and thus heighten performance efficiency at various loading conditions. This course of action is referred to as the MTPA mode and is a standard driving technique in IPMM drives.

The equation below describes the maximum voltage magnitude $V_{s m}$ that can be applied to the motor windings by the three-phase inverter [34], [35]:

$$
V_{d}^{2}+V_{q}^{2} \leq V_{s m}^{2}
$$

Assuming that the voltage drop across the winding resistance is small, substituting the machine voltage equations at steady state into the above yields [34], [35]

$$
\left(-\omega L_{q} i_{q}\right)^{2}+\left(\omega\left(L_{d} i_{d}+\lambda\right)\right)^{2} \leq V_{s m}^{2} .
$$

This equation can be rearranged as follows:

$$
\frac{\left(i_{q}\right)^{2}}{L_{q}^{-2}}+\frac{\left(i_{d}+\frac{\lambda}{L_{q}}\right)^{2}}{L_{d}^{-2}} \leq\left(\frac{V_{s m}}{\omega}\right)^{2}
$$

The preceding equations indicate that the dq-current selection is limited not only by the stator current magnitude but also the maximum stator voltage magnitude. While the limit on the stator current magnitude is a constant circle in the dq-current plane, the voltage limit is an ellipse that shrinks as the motor speed increases. When the point that corresponds to the commanded torque on the MTPA curve is no longer inside the voltage-limit ellipse, the motor must operate in FW mode. Operation in this mode allows for high motor speeds at the cost of lower motor torque. Figure 3-5 illustrates the MTPA, 
MTPV, and FW trajectories when the speed of the motor is below and above the rated speed of $123 \mathrm{rad} / \mathrm{sec}$.

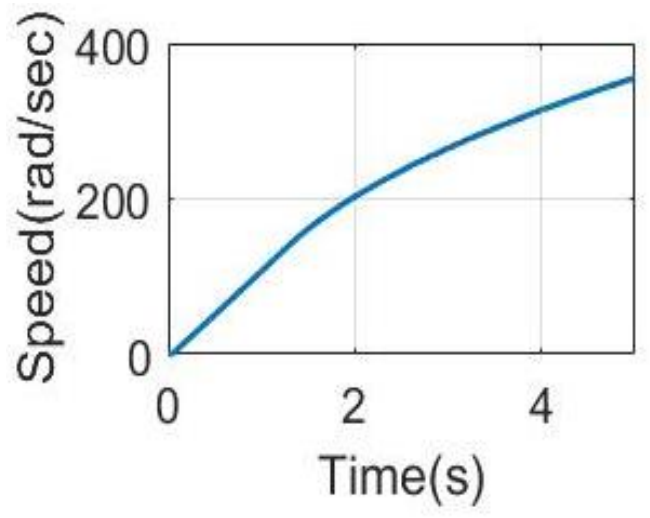

(a)

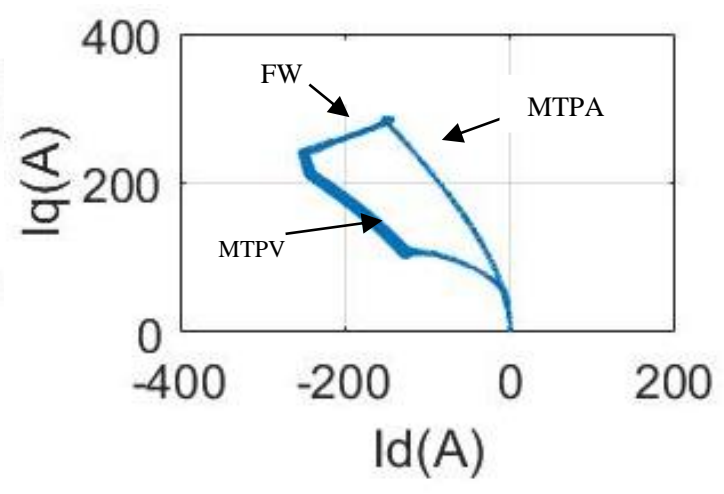

(b)

Figure 3-5 (a) Speed of the motor. (b) MTPA, MTPV, and FW trajectories.

Analytical expressions of the MTPA curve found in [32],[33] produce the following:

$$
\begin{gathered}
i_{q}=\sqrt{\frac{\lambda}{\left(L_{d}-L_{q}\right)} i_{d}+i_{d}^{2}} \\
i_{d}=\frac{\sqrt{4\left(L_{d}-L_{q}\right)^{2} i_{q}^{2}+\lambda^{2}}-\lambda}{2\left(L_{d}-L_{q}\right)}
\end{gathered}
$$

Analytical expression of the MTPV curve found in [34], [35] is as follows:

$$
\begin{aligned}
i_{d}=\frac{L_{q}}{L_{q} L_{d}-L_{d}^{2}} & \frac{\lambda_{P M}}{4}-\frac{\lambda_{P M}}{L_{d}}- \\
& \sqrt{\left(\frac{L_{q}}{L_{q} L_{d}-L_{d}^{2}} \frac{\lambda_{P M}}{4}\right)^{2}+\frac{1}{2}\left(\frac{V_{s m}}{\omega_{r} L_{d}}\right)^{2}}
\end{aligned}
$$




$$
\begin{gathered}
i_{q}=\sqrt{\left(\frac{V_{s m}}{\omega_{r} L_{d}}\right)^{2}+\left[\frac{1}{4} \frac{\lambda_{P M}}{L_{q}-L_{d}}-P\right]^{2}} \\
\mathrm{P}=\sqrt{\left(\frac{1}{4} \frac{\lambda_{P M}}{L_{q}-L_{d}}\right)^{2}+\frac{1}{2}\left(\frac{V_{s m}}{\omega_{r} L_{q}}\right)^{2}}
\end{gathered}
$$

An incoming torque command is plotted against the MTPA curve. When motor speed exceeds the limits of the MTPA curve, the controller tracks FW along the constant torque curve. When the commanded torque is no longer valid at any speed, the controller follows the MTPV curve.

\subsubsection{Cost Function.}

The cost function is the principle distinction among MPC and other predictive control procedures. It is a function that contains multiple sub-functions, which are set according to system requirements. The quality of speed tracking is dependent on the quality of the reference current tracking. Therefore, the main component of the cost function is an error term between the reference current and the predicted value of the current.

$$
J=\left|I_{\text {ref }}-I(k+1)\right|
$$

Another feature of MPC is its ability to add system constraints to the cost function with their specific weighting factor, which allows for adjusting the level of compromise between other function terms. However, upon introducing the additional terms to the cost function, the influence of the main terms diminishes to some extent, and an optimization is therefore required to find the most suitable solution to the control problem [36]. Some of the additional constraints in the proposed system are as follows:

(a) Voltage ripple minimization 
(b) Switching frequency minimization

(c) Limits to phase current and phase voltage

(a) Voltage ripple minimization: The input phase voltage should not switch between high values, as it may give rise to transients. To avoid switching between high voltage levels, the voltage ripple minimization factor is added to the cost function. This minimization factor is defined as the distance between the measured value of the voltage at the current state and at the future state (e.g. one step forward in time). The general form of this constraint is as follows:

$$
J=\lambda|| v(k+1)-v(k) \|
$$

(b) Switching frequency minimization: The switching of a large number of MOSFETs may prompt switching losses and issues of electromagnetic interference. The number of switching states that change at each sampling time can be minimized by adding a factor $(f)$ in the cost function multiplied by an appropriate weighting factor.

$$
J=\lambda\|v(k+1)-v(k)\|+\lambda_{1} f
$$

Here, $f$ is the number of switches that change their position from off to on, or vice versa, on the application of a new switching matrix. From (1), the switch matrix at instant $k$ and $k+1$ is given by $S W_{\text {matrix }}(k)$ and $S W_{\text {matrix }}(k+1)$, respectively. Here, $f$ is the elementwise addition of the difference of the two matrices.

$$
f=\sum_{i=1}^{N}\left|S W_{\text {matrix }}(k+1)-S W_{\text {matrix }}(k)\right|
$$

(c) Limits to the phase current and phase voltage: Motor windings and MOSFETs are designed for a specific current and certain voltage ratings. In order for the system to work within the limitations of current and voltage, another nonlinear term is added to the cost 
function that becomes active only when the value of specified variables exceeds the limitations [36]. The function is chosen to increase the value of the cost function to an especially high value, so that particular switching state is not selected. The mathematical expression of the function is as follows:

$$
F_{\text {lim }}\left(i^{p}\right)= \begin{cases}\infty, & \text { if }\left|i^{p}\right|>I_{\text {max }} \\ 0, & \text { if }\left|i^{p}\right|<I_{\text {max }}\end{cases}
$$

\subsubsection{Predictive Model.}

For an MMC with $n$ sub-modules, the total number of possible voltage selections using different combinations of cell modules is $2 n+1$ per phase and given by

$$
V=\left[\begin{array}{lllll}
-n V_{\text {cell }} & . & 0 & . . & n V_{\text {cell }}
\end{array}\right]
$$

Using these as input to the discrete machine model (3), $2 n+1$ different predictions of current are made for the next sampling instant $(k+1)$. The predictive control algorithm for the proposed scheme is a three-fold process [37]:

(a) The first stage is the prediction of the IPMM state (current) for every possible voltage selection (21) using the discrete model (3) of the drive.

(b) The second stage is the evaluation of a cost function for every predicted state; this cost function is a representation of the control goals.

(c) The third stage is the adjustment of the switch matrix of the MMC to apply the selected voltage vector to the machine during the next sampling interval.

At every instant, MPC evaluates the cost function $2 n+1$ times, which makes this scheme highly calculation intensive. Changing the switch matrix to reduce the tracking error that is already within the bounds increases the switching frequency of the MMC and leads to a higher rate of change of the voltage states. Thus, to reduce the amount of 
calculation, expedite the voltage selection decision, and reduce the $d v / d t$, the cost function is dependent on the tracking error bound as explained below.

a) Low error mode: If the error between the reference current and the current at instant $k$ is below a certain allowed error value $E_{l}$, and $I(k+1)<I_{\max }$, then the previous voltage selection is retained without evaluating the cost function again.

$$
\left|I_{\text {ref }}-I(k)\right|<E_{l}
$$

b) Within the error bound: If the error between the reference and the actual variable is between $E_{l} a n d E_{h}$, the following cost function is evaluated.

$$
J=\lambda_{1}\left|I_{\text {ref }}-I(k+1)\right|^{2}+\lambda_{2}|V(k)-V(k-1)|+\lambda_{3} f+F_{\text {lim }}
$$

Here, $\lambda_{1}, \lambda_{2}$ and $\lambda_{3}$ are weighting coefficients. The first term in the cost function penalizes the current tracking error, the second term minimizes the voltage ripple, and the third term minimizes the switching frequency. In this mode, the tendency is to return to the low error mode as well as reduce the phase voltage ripple and switching frequency. In low error mode, if $I(k+1)>I_{\max }$, then the cost function is evaluated to ensure that the system works within the safety of the current limits. In a steady state, which lacks substantial variation in the reference, the system operates in this mode.

c) High error mode: If the reference tracking error exceeds $E_{h}$, then the following cost function (27) is evaluated.

$$
J=\left|I_{\text {ref }}-I(k+1)\right|^{2}+F_{\text {lim }}
$$

In this mode, the control system returns the error to low error mode or within the error bound. 


\subsection{State of Charge Balancing}

For optimal performance of the MMC system, the voltage levels of all cells should be equal. Each cell has a different rate of discharge depending on its electrochemical characteristics. Thus, to ensure that all cells are working at the same terminal voltage, there is a need to incorporate a voltage-balancing algorithm within the MPC algorithm. The algorithm assigns priority to the reference tracking first and voltage balancing second. The principal is to lower the use of low-voltage cells $\left(C_{L V}\right)$ in comparison to cells with high voltage $\left(C_{H V}\right)$ to yield a rate of voltage drop that is less in $C_{L V}$ until the voltage of $C_{L V}=$ voltage of $C_{H V}$.

\subsubsection{Algorithm.}

This algorithm is explained for $p^{\text {th }}$ phase. The same rules would apply to any of the three phases. If the voltage selection by MPC $\left(V_{r e q}\right)$ is zero voltage, then it would indicate that by turning each column of the switch matrix of that phase is given by $\left[S_{p k 1} S_{p k 2} S_{p k 3} S_{p k 4}\right]$ to $\left[\begin{array}{llll}1 & 0 & 1 & 0\end{array}\right]$ sequence. The voltages of all the battery cells are constantly sensed by a sensor and sent to the controller, which arranges the voltage levels in a sorted sequence. The sorted sequence is the updated voltage levels of all cells as arranged in descending order. If the voltage selection $\left(V_{\text {req }}\right)$ is positive, then the MPC would choose top $l=\frac{V_{\text {req }}}{V_{\text {cell }}}$ cells out of $n$ battery cells from the sorted sequence. The MPC then gives these $l$ sub-modules a switching sequence that derives from $\left[\begin{array}{llll}1 & 1 & 0 & 0\end{array}\right]$

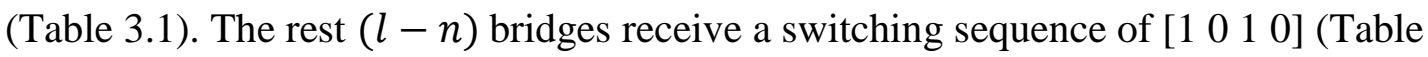
3.1). If the required voltage $\left(V_{r e q}\right)$ is negative, then the MPC again selects top $l$ cells, as 
explained above, and assigns them a switching sequence of [ $\left[\begin{array}{llll}0 & 0 & 1 & 1\end{array}\right]$. The rest $(l-n)$ bridges receive a switching sequence of [ $\left[\begin{array}{llll}1 & 0 & 1 & 0\end{array}\right]$. 


\section{CHAPTER 4. VALIDATION OF RESULTS}

The performance of the proposed control scheme has been tested through simulation using MATLAB/Simulink models. The simulations subjected the motor to a vehicle load and a speed command that utilize the urban dynamometer driving schedule (UDDS) provided by the Environmental Protection Agency (EPA). A motor with the following parameters was used:

Table 4-1 Motor Parameters

\begin{tabular}{|c|c|c|c|c|l|}
\hline$L_{d}$ & $L_{q}$ & $T_{\max }$ & $\lambda$ & $\omega_{n}$ & $\mathrm{P}$ \\
\hline $1.59 \mathrm{mH}$ & $2.05 \mathrm{mH}$ & $410 \mathrm{Nm}$ & $0.175 \mathrm{~Wb}$ & $123 \mathrm{rad} / \mathrm{sec}$ & 8 \\
\hline
\end{tabular}

Reference currents were generated through a current controller that adhered to both MTPA and FW control. The following MATLAB simulation results reveal the performance of the MMC topology in realistic motor loading. The current reference generation using modern motor control methods (MTPA, MTPV, and FW) demonstrate the performance of the proposed control scheme in high-speed and low-speed regions.

\subsection{UDDS Tracking}

The simulation yielded promising results for the proposed control of an MMC three-phase inverter. In Figure 4-1, the reference speed is tracked well within an error of $1 \%$, even at a sampling frequency of $5 \mathrm{kHz}$ with 50 sub-modules. 


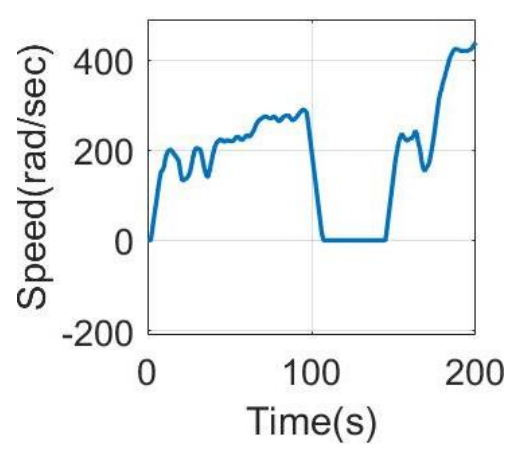

(a)

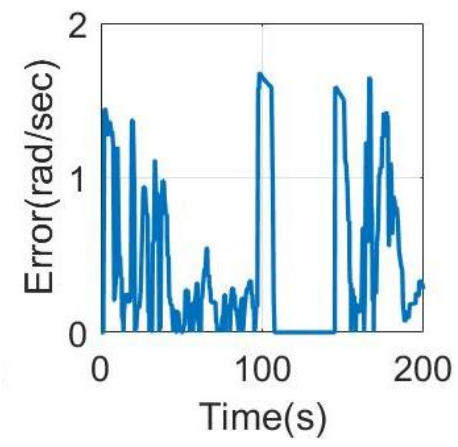

(b)

Figure 4-1 Speed tracking: (a) UDDS drive cycle tracking. (b) speed tracking error.

\subsection{Effect of Weighting Factor on System Performance}

The cost function consists of a voltage ripple minimization constraint. Upon assigning high weights to the constraint, the quality of the voltage waveform improved. However, torque ripple and speed tracking error became high, as Figures 4-2 and 4-3 illustrate.

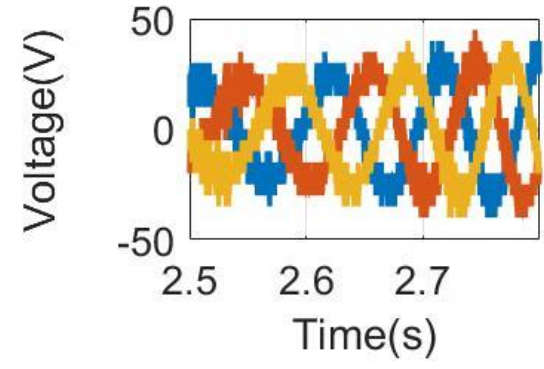

(a)

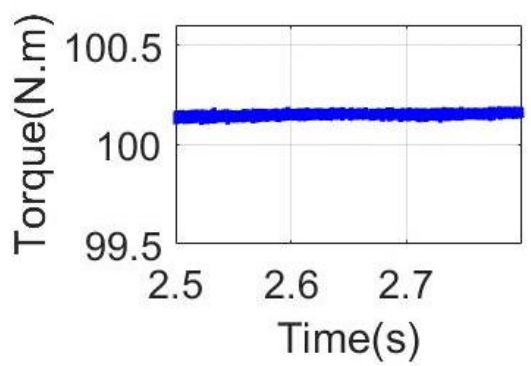

(c)

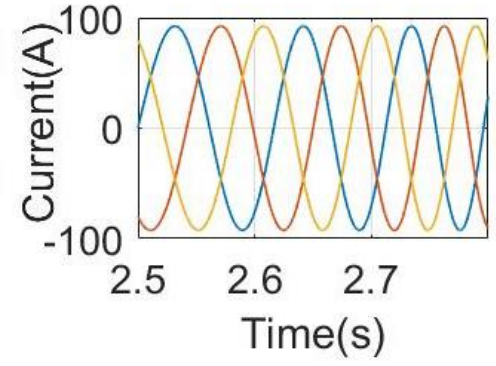

(b)

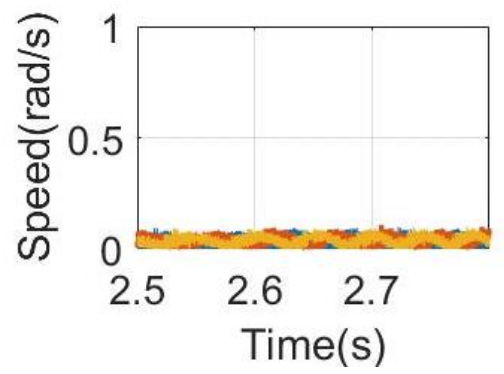

(d)

Figure 4-2 For $\lambda_{1}=1, \lambda_{2}=0.001, \lambda_{3}=0$; (a) three-phase voltage. (b) three-phase current. (c) torque ripple. (d) error between reference and actual speed. 


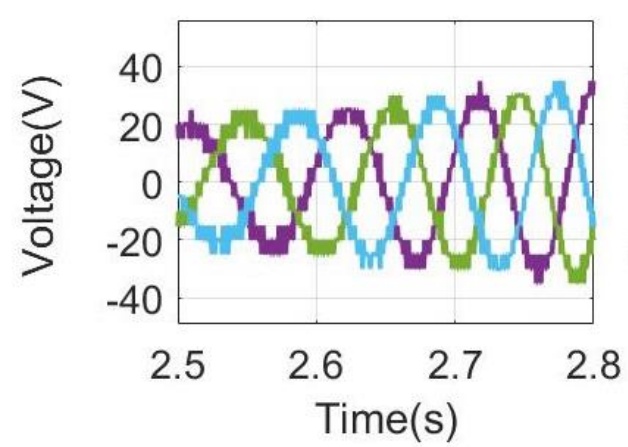

(a)

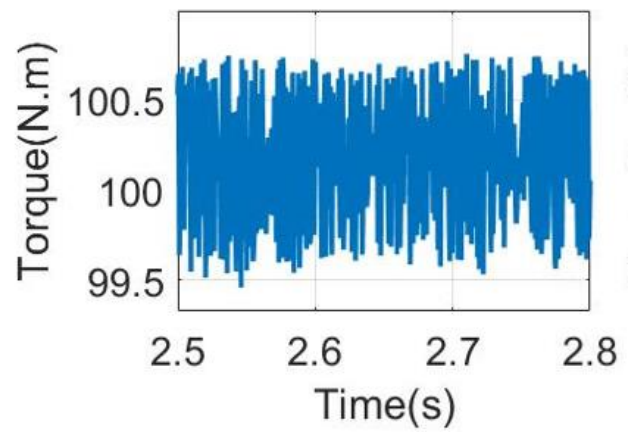

(c)

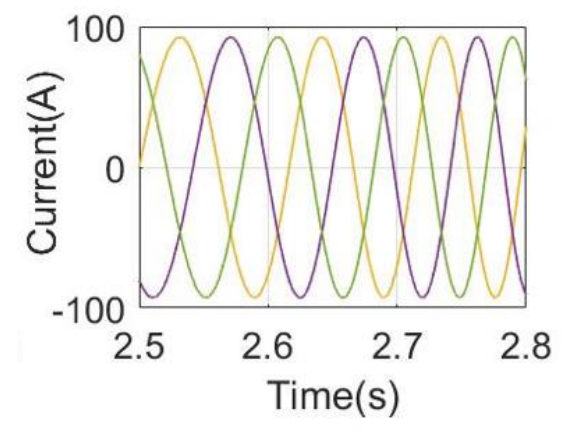

(b)

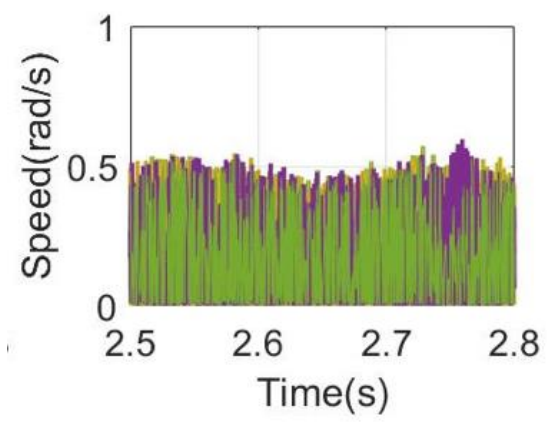

(d)

Figure 4-3 For $\lambda_{1}=0.8, \lambda_{2}=0.007, \lambda_{3}=0$; (a) three-phase voltage. (b) three-phase current. (c) torque ripple. (d) error between reference and actual speed.

\subsection{Effect of Number of Sub-Modules on System Performance}

The number of sub-modules in an MMC has a positive impact on tracking error, phase voltage ripple, and torque ripple. As Figure 4-4 indicates, with the increase in the number of sub-modules from 5 to 50 at $20 \mathrm{kHz}$, the phase voltage approached a sinusoidal waveform. The tracking error and torque ripple also diminished. 


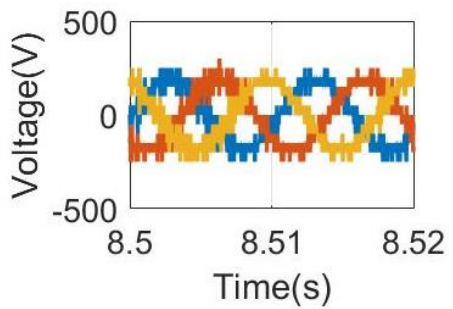

(a)

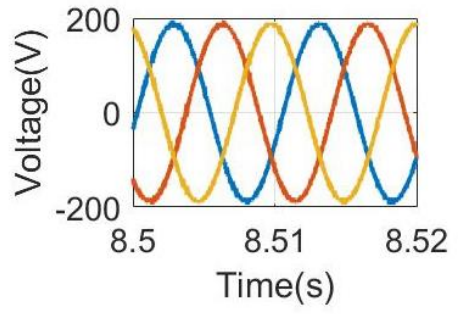

(d)

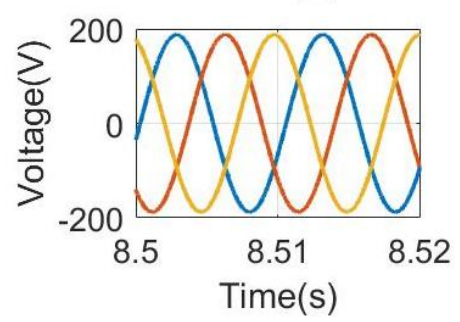

(g)

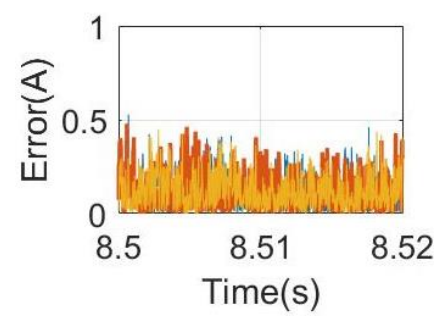

(b)

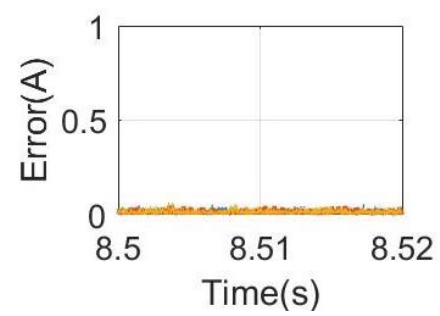

(e)

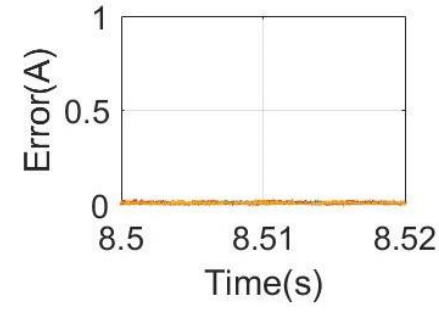

(h)

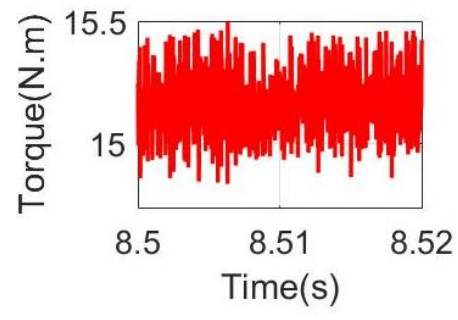

(c)

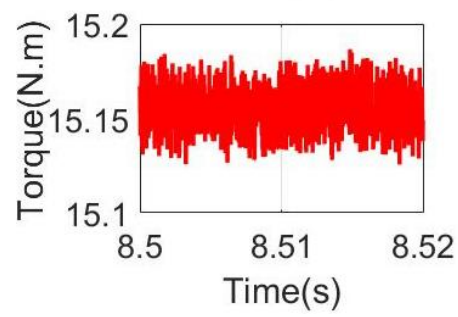

(f)

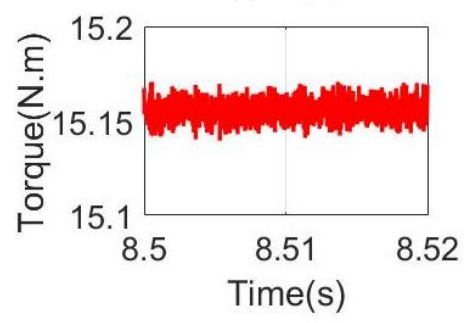

(i)

Figure 4-4 Number of sub-modules: five (first row); fifty (second row); one hundred (third row); phase voltages (a), (d), (g). current tracking error (b), (e), (h). torque ripple (c), (f), (i).

\subsection{Effect of Sampling Frequency on System Performance}

As the sampling frequency increased, the tracking naturally improved, as the control input to reduce tracking error was provided more quickly. However, because of the faster sampling frequency, the DSP needed to perform all of the optimization calculations within a small sample instant, which in turn advanced the implementation costs of the control scheme. On the other hand, a lower sampling frequency would result in poor tracking of the reference signal. 


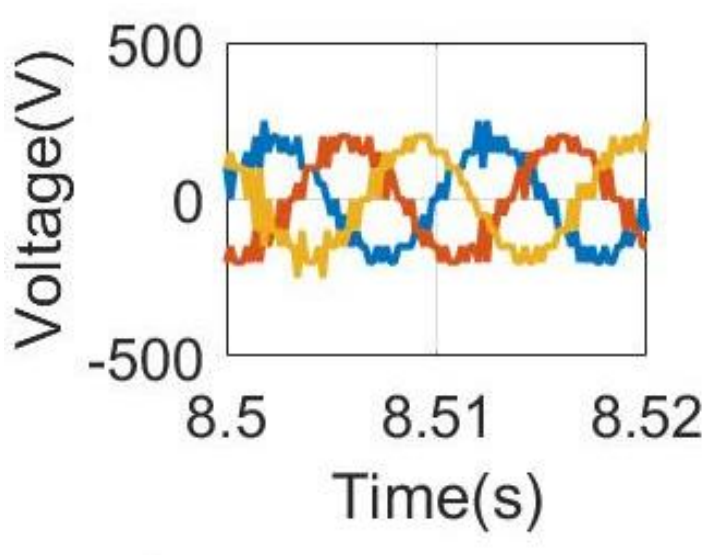

(a)

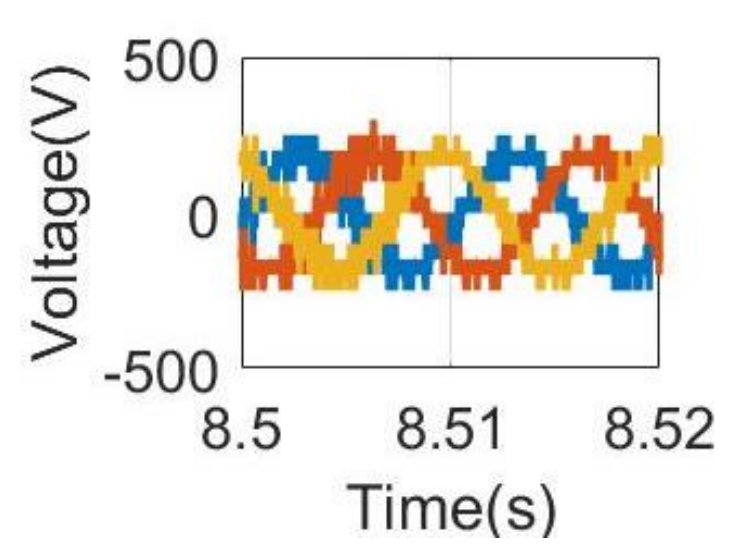

(c)

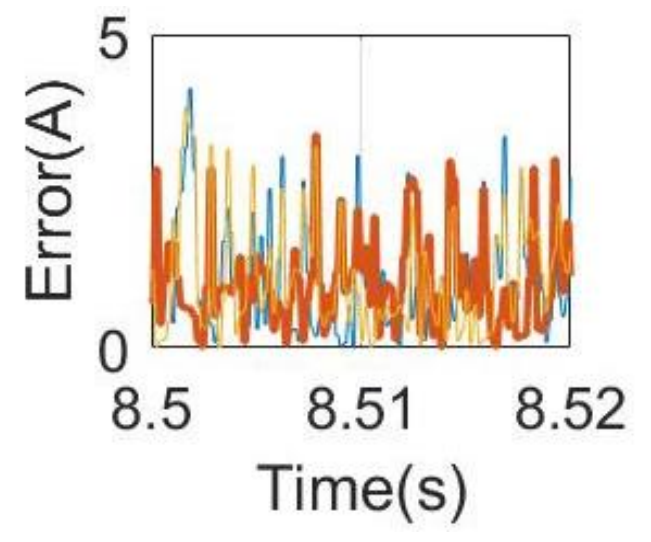

(b)

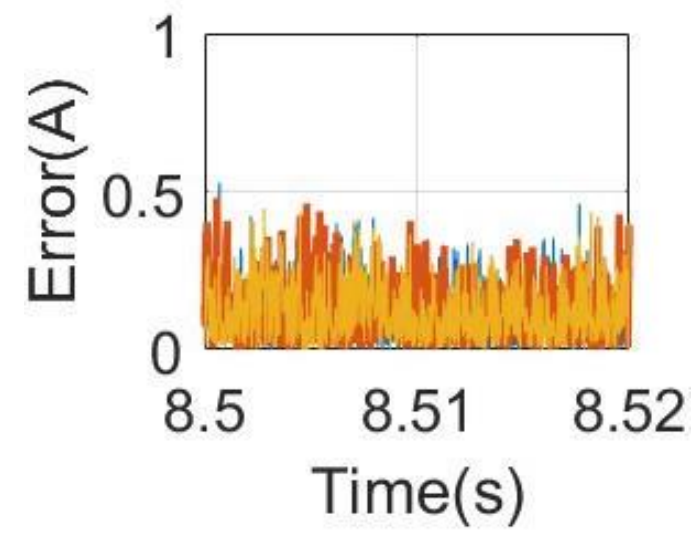

(d)

Figure 4-5 Effect of sampling frequency sub-modules in MMCs (five per phase): (a) phase voltages at $5 \mathrm{kHz}$, (b) error in reference tracking at $5 \mathrm{kHz}$, (c) phase voltages at $50 \mathrm{kHz}$, (d) error in reference tracking at $50 \mathrm{kHz}$.

This problem can be overcome by increasing the number of sub-modules in an MMC.

Figure 4-5 and 4-6 reveal that the tracking error of five sub-modules at a $50 \mathrm{kHz}$ sampling frequency is similar to the tracking error of 50 sub-modules at the $5 \mathrm{kHz}$ sampling rate. Increasing the number of sub-modules in an MMC also improved the tracking at lower frequencies because of the presence of more voltage selections to the MPC, which can allow for more accurate voltage selection and therefore result in superior tracking. 


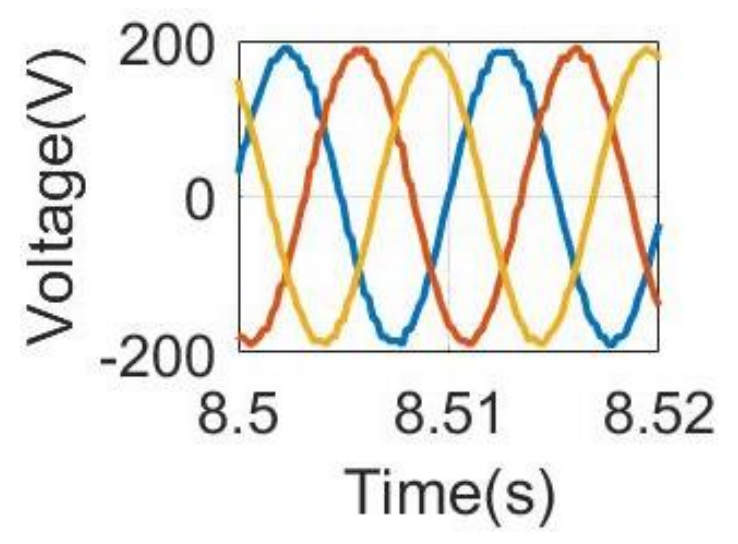

(a)

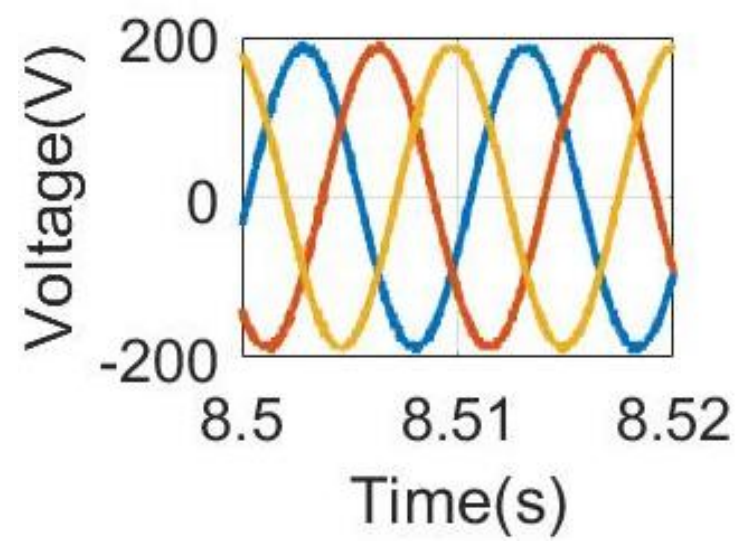

(c)

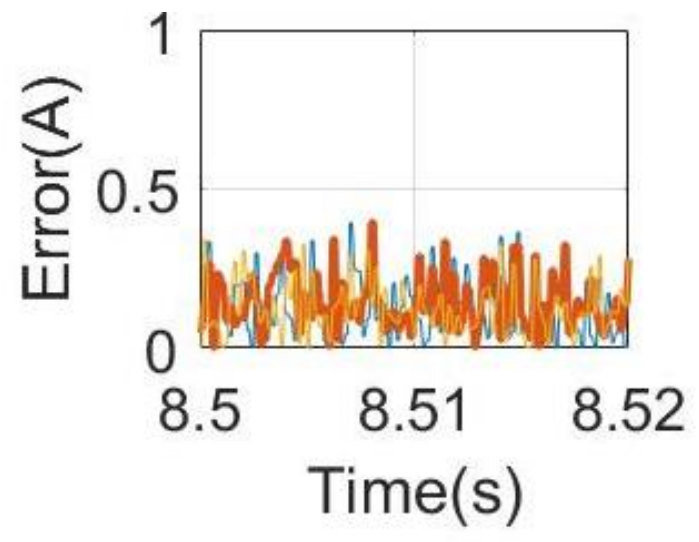

(b)

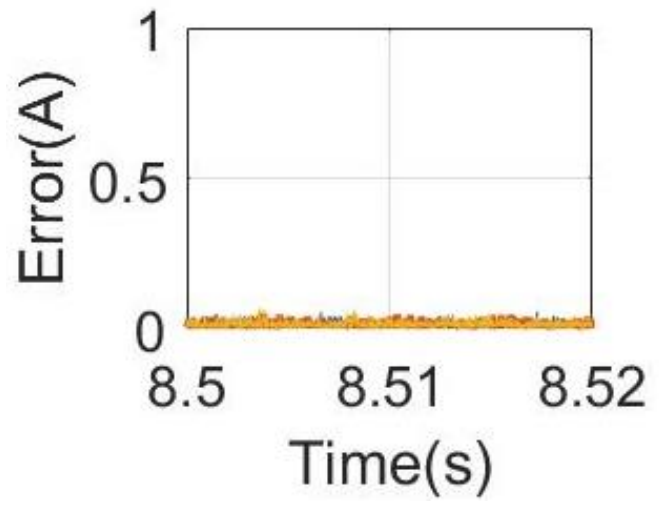

(d)

Figure 4-6 Effect of sampling frequency on MMC output (a) three-phase voltages at $5 \mathrm{kHz}$, (b) error in reference tracking at $5 \mathrm{kHz}$, (c) phase voltages at $50 \mathrm{kHz}$, (d) error in reference tracking at $50 \mathrm{kHz}$.

\subsection{MTPA Tracking}

The MTPA tracking was tested by applying a 100\% command torque for five seconds (see Figure 4-7). As the speed of the motor surpassed the rated speed (123 rad/s), the motor could not follow the MTPA trajectory. In order to provide the maximum torque, the motor entered into the FW and MTPV regions, and the output torque consequently began to drop. 


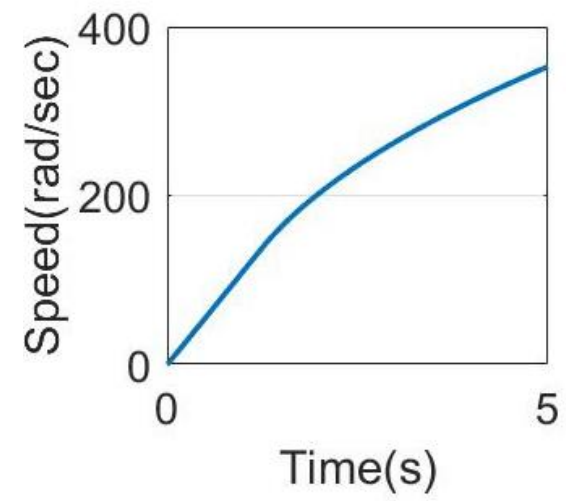

(a)

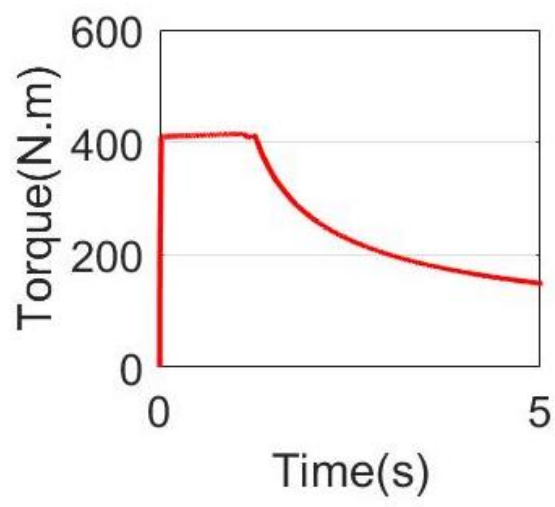

(c)

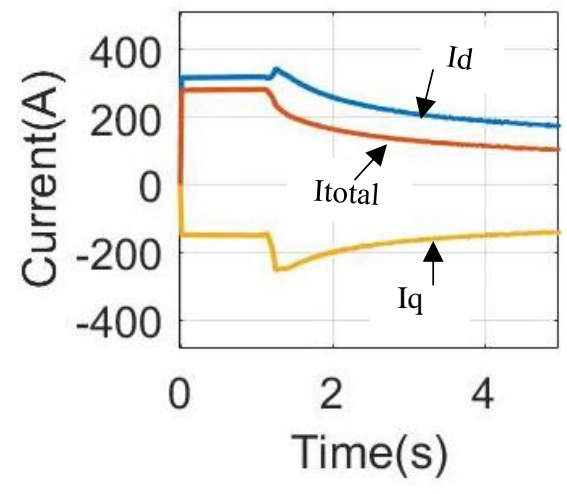

(b)

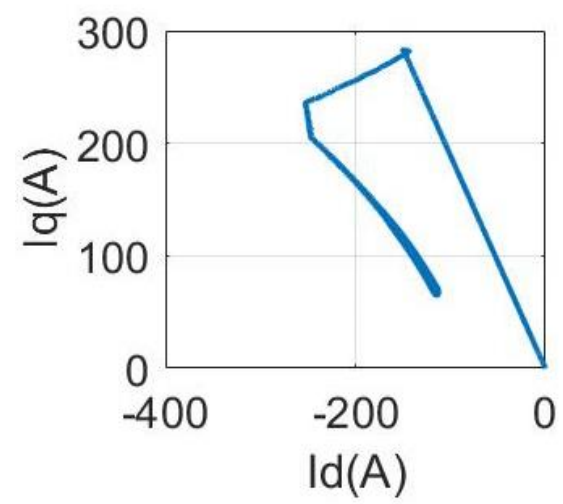

(d)

Figure 4-7 MTPA tracking at maximum command torque: (a) speed tracking. (b) motor current. (c) electromechanical torque. (d) MTPA curve.

\subsection{Switching Loss}

Switching losses of a MOSFET derive from [38], where $V_{i n}=V_{d s}$ (drain-to-source voltage), $I_{o u t}=I d$ (drain current), $\mathrm{f}_{\mathrm{sw}}$ is the switching frequency, and $t_{\text {on }}$ and $t_{\text {off }}$ depend on the time the driver takes to charge the MOSFET.

$$
P_{s w}=\frac{1}{2} \mathrm{~V}_{\text {in }} \times \mathrm{I}_{\text {out }} \times \mathrm{f}_{\mathrm{sw}} \times\left(t_{\text {on }}+t_{\text {off }}\right)
$$

In MPC, the switching period is not constant, so the switching losses in a MOSFET are calculated by 


$$
P_{m p c}=V_{i n} \frac{t_{o n}+t_{o f f}}{2} \sum_{m=1}^{h}\left|I_{o u t}\right| .
$$

Each module of the presented MMC topology consists of four MOSFETs (H bridge). Whenever a group of MOSFETs in an MMC turns on or off, it is safe to assume for a given reference current that the $I_{\text {out }}$ is the same for all of them, $t_{\text {on }}$ and $t_{\text {off }}$ can be set by choosing an appropriate gate driver, and $\mathrm{V}_{\mathrm{dc}}$ depends on the number of sub-modules in the MMC. Effectively switching losses depends on the number of times switches turn on or off; thus, a normalized switching loss is discussed here, as $V_{d c} \frac{t_{o n}+t_{o f f}}{2} \sum_{m=1}^{h}\left|I_{o u t}\right|$ was the same for all of them. The following simulation results demonstrate the variation of switching losses in an MMC with the cost function, number of MMC modules, and sampling frequency.

\subsubsection{Effect of Number of Sub-Modules.}

The number of sub-modules in an MMC has a constructive impact on tracking error, phase voltage ripple, and torque ripple (section 4.3). As Figure 4-8 illustrates, at $20 \mathrm{kHz}$ sampling frequency, the increase in number of sub-modules from 10 to 50 reduced the switching losses by more than one-third of the value at 10 modules per phase without affecting the reference tracking. According to Equation (29), as the number of modules increased, the voltage $V_{d s}$ across MOSFETs decreased, which in turn diminished the switching losses. 


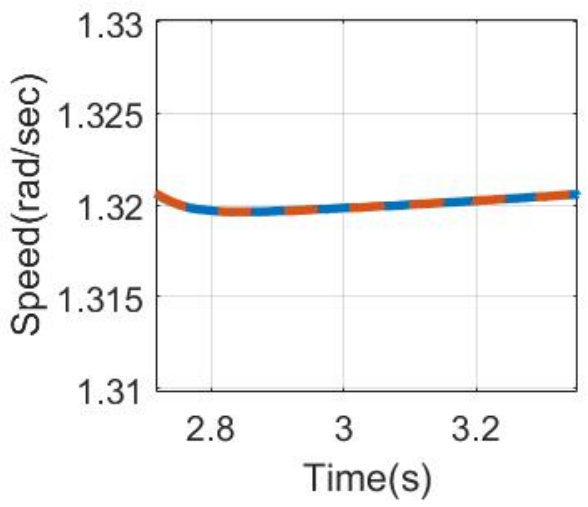

(a)

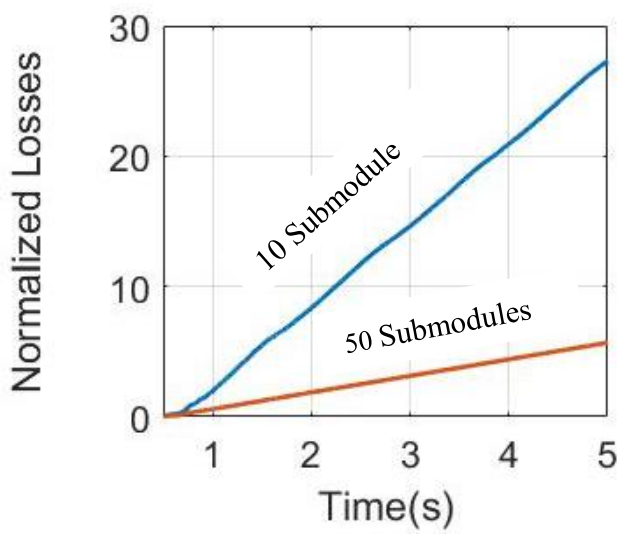

(b)

Figure 4-8 (a) Speed tracking error in 10 sub-modules (dashed) and 50 sub-modules (orange); (b) Normalized switching losses in 10 sub-modules and 50 sub-modules.

\subsubsection{Effect of Sampling Frequency.}

Based on section 4.4, the effect of sampling frequency on tracking reference current is positive. However, as the sampling frequency increased, the number of updated switch matrix transferred to MMC per unit time did as well, thus leading to a higher switching frequency of MOSFETs. Therefore, the switching loss increased, as Figure 4-9 indicates. As the sampling frequency changed from $10 \mathrm{kHz}$ to $50 \mathrm{kHz}$, the losses increased, with almost no effect on speed tracking error. 


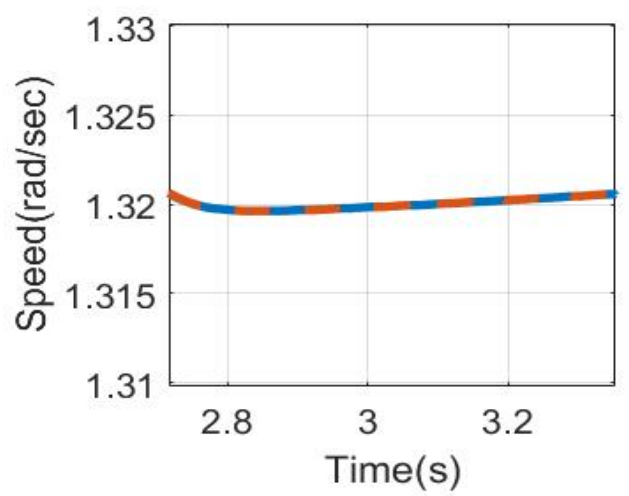

(a)

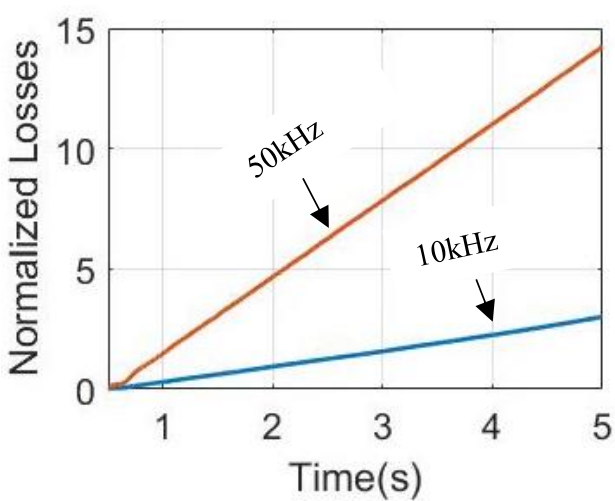

(b)

Figure 4-9 (a) Speed tracking error at $10 \mathrm{kHz}$ and $50 \mathrm{kHz}$ sampling frequency. (b) normalized switching losses at $10 \mathrm{kHz}$ and $50 \mathrm{kHz}$ sampling frequency.

\subsubsection{Effect of the Cost Function.}

In Figure 4-10, the difference in normalized switching losses with varying cost function is depicted. Evidently, with the addition of an $f$ component (see eq. 21) to the cost function by setting $\lambda_{3} \neq 0$, the switching losses of MOSFETs in an MMC diminished considerably without impacting the speed tracking accuracy.

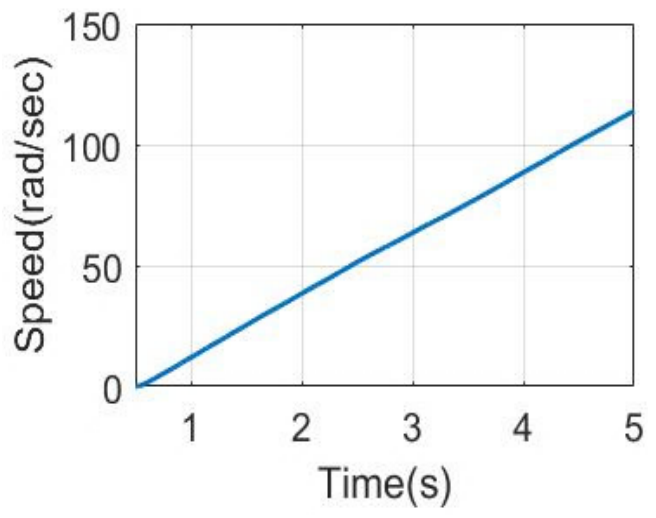

(a)

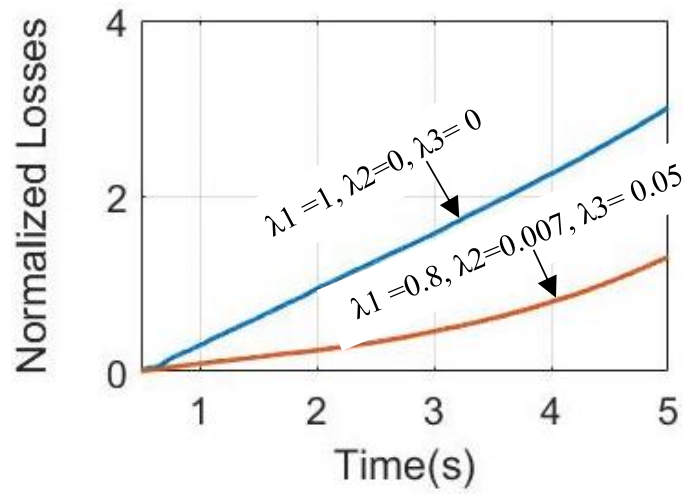

(b)

Figure 4-10 (a) Reference speed. (b)Switching losses variation with Cost function. 


\subsection{Effect of Cost Function on Voltage Waveform and THD}

As Figure 4-11 conveys, the motor was given a reference speed of $55 \mathrm{rad} / \mathrm{sec}$. The MMC contained fifty sub-modules, and the control system was sampled at $20 \mathrm{KHz}$. In addition, by including the voltage ripple minimization term $|v(k+1)-v(k)|$ and switching frequency reduction term, the phase voltage THD improved along with the phase voltage $d v / d t$.

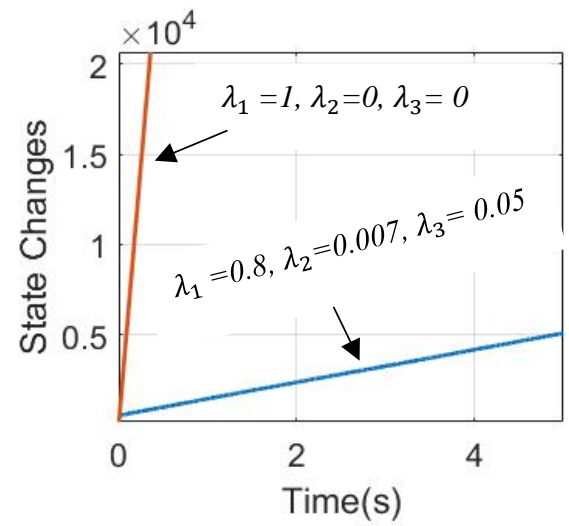

(a)

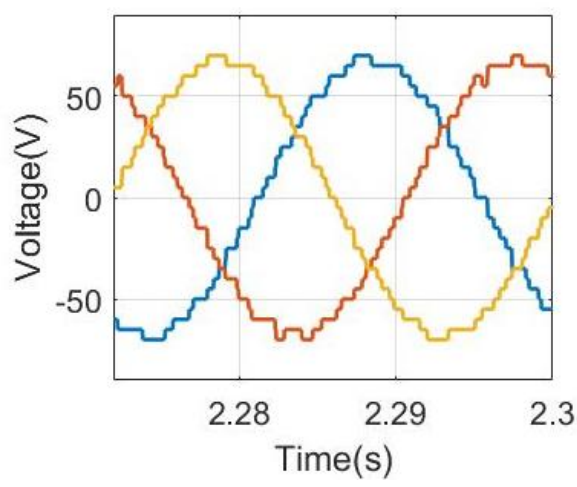

(c)

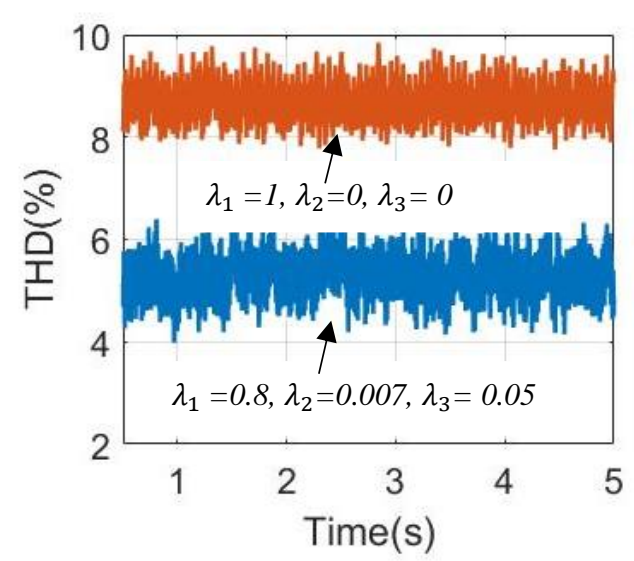

(b)

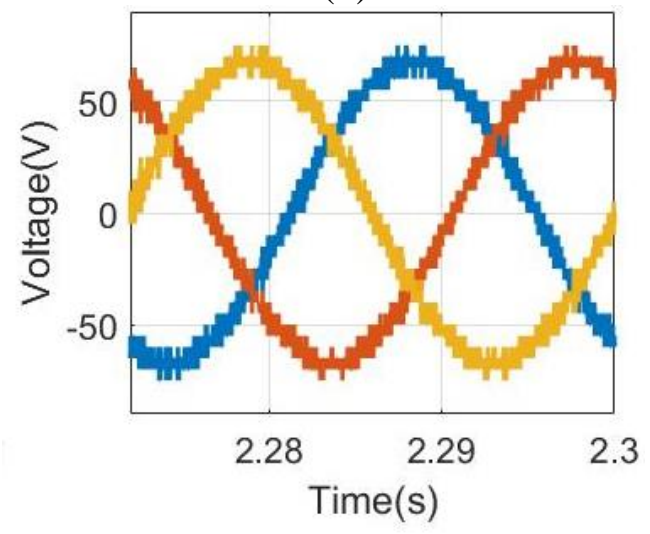

(d)

Figure 4-11 (a) Rate of change of voltage states at the output of MMC. (b) variation of THD with cost function. (c) voltage waveform for $\lambda_{1}=0.8, \lambda_{2}=0.007, \lambda_{3}=0.05$. (d) voltage waveform for $\lambda_{1}=1, \lambda_{2}=0, \lambda_{3}=0$. 


\section{CHAPTER 5. HARDWARE IMPLEMENTATION}

To test the proposed control strategy, a working prototype of the drive system has been designed. It consists of following parts:

(1) A three-phase, $3.3 \mathrm{~kW}$ IPMM with a rated speed of 1,500 rotation per minute (RPM) and input phase-to-phase voltage of $96 \mathrm{~V}$ as the test motor

(2) OPAL-RT 4200 as a controller to run the proposed MPC control scheme; OP4200 is equipped with FPGA-based input-output and real-time solvers, with which it can solve calculation-intensive MPC optimizations within one sample time, and it is used in academia for hardware in the loop (HIL) testing of systems

(3) As each phase, an MMC with 10 sub-modules, each with the $4.8 \mathrm{~V} \mathrm{Li-ion} \mathrm{cell;}$ accordingly, the MMC sub-module is designed in ORCAD

\subsection{Design of MMC Sub-Module}

The proposed control scheme connects all of the sub-modules of an MMC in series. Therefore, the voltage of each sub-module is equal to the cell voltage, but the total current passing through each sub-module is the sum of the currents that are generated by individual cells. Hence, the switching devices should be capable of handling high currents.

$$
\begin{gathered}
P_{\text {motor }}=V_{r m s} I_{r m s} \\
3.3 * 10^{3}=\left(\frac{96}{\operatorname{sqrt}(2)}\right) I_{r m s} \\
I_{r m s}=48.60 \mathrm{~A} \\
\mathrm{I}_{\mathrm{p}}=48.6 * \operatorname{sqrt}(2)=68.72 \mathrm{~A}
\end{gathered}
$$


Here, $P_{\text {motor }}$ is the power rating of the selected IPMM, $V_{r m s}$ is the phase voltage across the motor, and $I_{r m s}$ is the root mean square value of the phase current that is flowing in the IPMM.

The MOSFET that can withstand the heating caused by $I_{r m s}$ is selected. Since each sub-module has a $4.8 \mathrm{~V}$ cell, the maximum voltage stress across the MOSFET due to battery cell can be $2.5 \mathrm{~V}$. However, the MOSFET switches on and off to a large amount of current, as discussed above, which generates substantial heating and creates more voltage stress $L_{\text {line }}\left(\frac{d i}{d t}\right)$ due to line inductances that are given by $L_{\text {line }}$. To secure the circuit from the voltage stress that is generated and the heating due to the high rms current, CSD16411Q3 25-V N-Channel Power MOSFET is selected as a switching device in each sub-module [39]. It can withstand a drain current of $50 \mathrm{~A}$ and source-todrain voltage of $25 \mathrm{~V}$.

\subsubsection{Gate Driver Circuit.}

Each module consists of four MOSFETs that require gate signals to turn on or off to yield positive, negative, or zero voltage at the output of the sub-module. The gate driver is UCC21520, an isolated dual-channel gate driver with a 4A source and a 6A sink-peak current [40]. A disable pin shuts down both outputs simultaneously when set high and allows for normal operation when left floating or grounded. It is designed to drive power MOSFETs up to a $5 \mathrm{MHz}$ switching frequency along with significantly less propagation delay and pulse width distortion [40]. 


\subsubsection{Buffer for Gate Signals.}

Because of high-frequency components, such as MOSFETs, on the board, the strength of the gate signal from the MPC controller becomes weakened, which may lead to a lag in turning the switches on or off. To increase the strength of the gate signals from the controller, a buffer is added before the gate driver. The SN74LVC2G34 device is a dual buffer gate that performs the Boolean operation $\mathrm{Y}=\mathrm{A}$ in positive logic [41]. Figure 5-1 presents the design of the buffer and gate driver circuit in ORCAD.

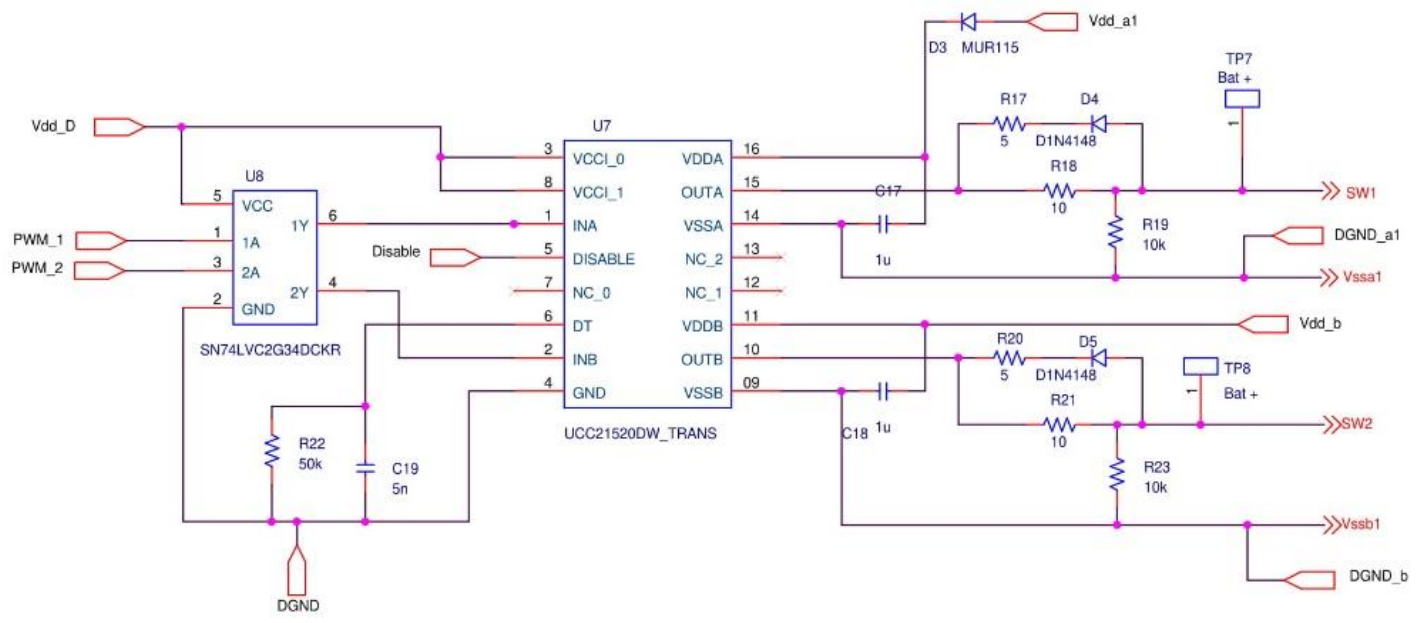

Figure 5-1 Schematics of buffer and gate driver circuit.

\subsubsection{Sensors.}

To measure the current and voltage across each sub-module and voltage across each phase, a current sensor and voltage sensor is required. A shunt resistor, which is connected in series with each cell, is designed to sense the current and voltage. This is a cost-effective means of sensing compared to the traditional use of Hall effect sensors. AMC1301 is selected as the operational amplifier (OP-AMP) to sense voltage across the 
shunt resistor. It is a precision isolation amplifier with a nominal gain of 8.2 [43]. The input of the AMC1301 is optimized for direct connection to shunt resistors or other low-voltage-level signal sources.

(a) Design of shunt resistor for current sensing: As discussed previously, the peak-to-peak current that flows through the sub-modules is $\pm 68.72 \mathrm{~A}$. Considering the peak current to be $70 \mathrm{~A}$, the shunt value can be calculated as

$R_{\text {shunt }}=\frac{ \pm 250 \mathrm{mV}}{ \pm 70 \mathrm{~A}}=3.57 \mathrm{~m} \Omega$.

Here, $\pm 250 \mathrm{mV}$ is the input voltage range of AMC1301 OP-AMP. The output of AMC1301 OP-AMP is a differential signal. This output must be calibrated to a single-ended form with a range between $0 \mathrm{~V}$ and $3.3 \mathrm{~V}$ before sending to the controller. According to the datasheet of AMC1301, the input range is $\pm 250 \mathrm{mV}$, with a nominal gain of 8.2 , and the output range is $\pm 2.05 \mathrm{mV}$. So, the peak-to-peak value of the output voltage for AMC1301 is $4.10 \mathrm{~V}$. To reduce it to $3.3 \mathrm{~V}$, another OP-AMP, OPA320, is added between the controller and AMC1301 [42]. The OPA320 gain is given by $\frac{3.24}{4.10}=0.79$.

(b) Resistors selection for OPA320: The differential amplifier gain is given by $\frac{R_{f}}{R_{i n}}=\frac{7.5 k \Omega}{4.7 k \Omega+4.7 k \Omega}=0.79$, where $R_{f}$ and $R_{i n}$ are the feedback and input resistor, respectively. Figure 5-2 illustrates the current sensor circuit. 


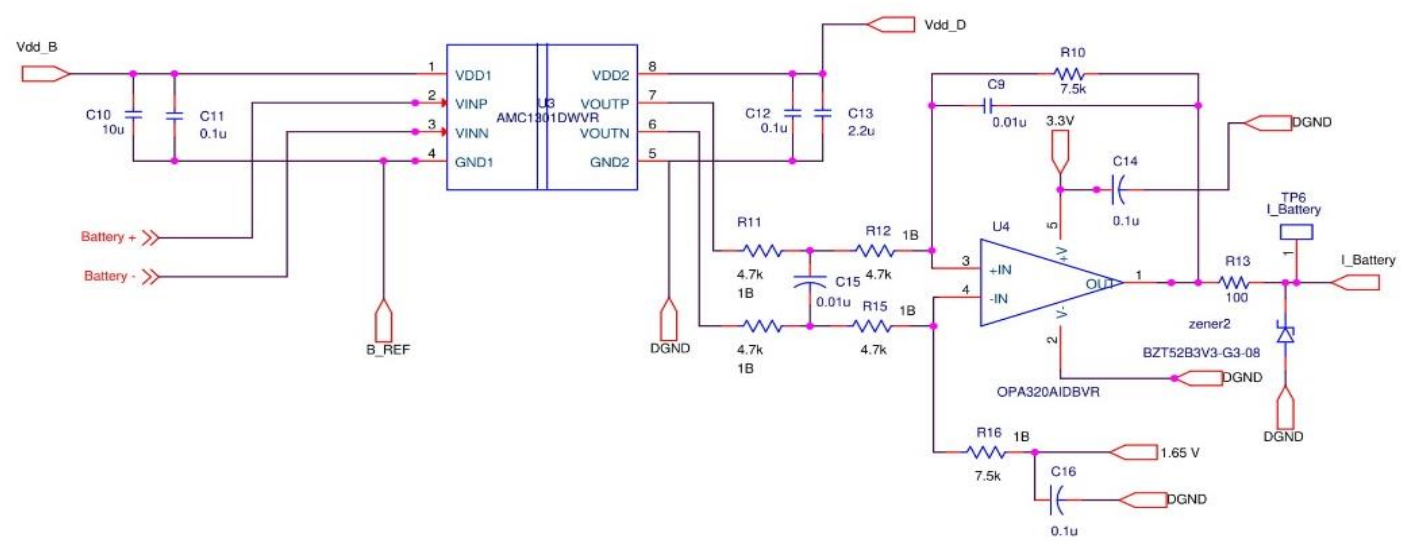

Figure 5-2 Schematics of the current sensor circuit.

(c) Design of shunt resistor for voltage sensing: The voltage sensor at the output is designed to measure the voltage of each phase. The selected IPMM has a phase-to-phase voltage of $96 \mathrm{~V}$. Thus, the maximum phase-to-neutral voltage is $48 \mathrm{~V}$. By including voltages due to line inductance, the maximum voltage that can be sensed is $60 \mathrm{~V}$. Therefore, the shunt resistor is designed at the output of each MMC.

$$
R_{\text {shunt }}=\frac{ \pm 250 \mathrm{mV}}{ \pm 60 \mathrm{~V}}=4.12 \mathrm{~m} \Omega
$$

Other components of the voltage sensor, such as an sensing OP-AMP (AMC1301), analog to digital converter (OPA320), feedback, and input resistor, are selected in the same way as the current sensor (see Figure 5-3). 


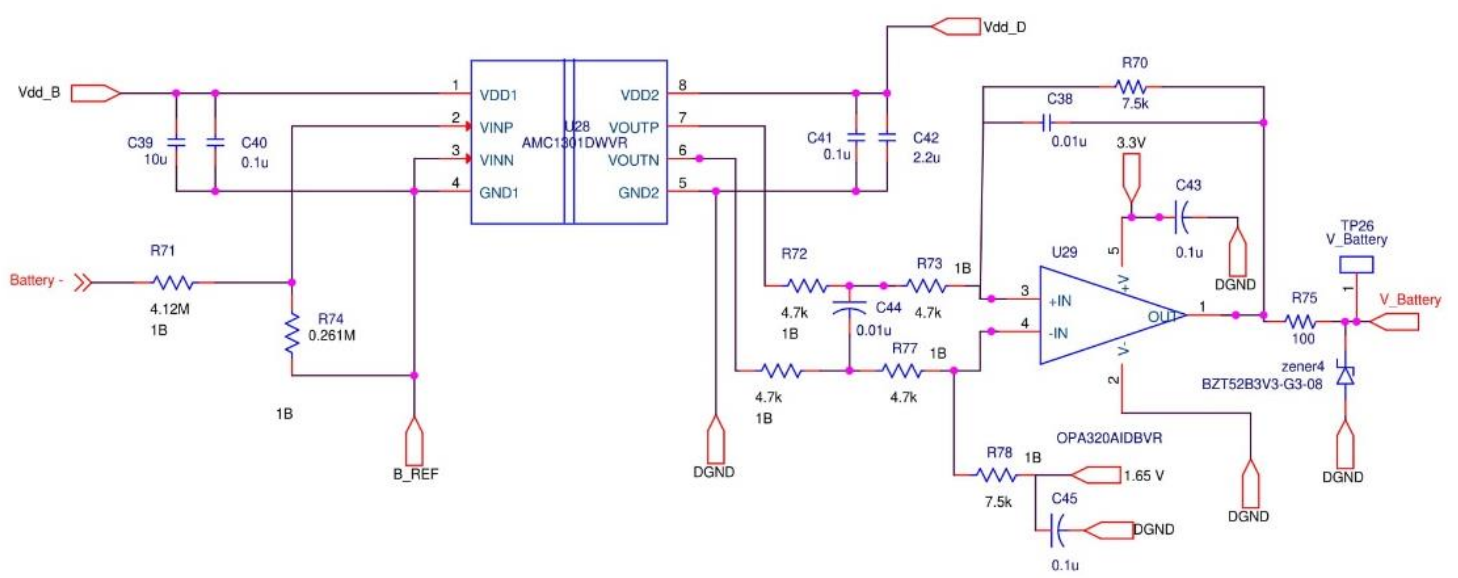

Figure 5-3 Schematics of voltage sensor.

\subsubsection{Protection Circuits.}

The MMC module involves an H-bridge circuit that has a risk of shoot-through if two switches in the same leg turn on at the same time. In a shoot-through condition, a large amount of current flows through the MOSFETs, which can damage them. To protect the circuit from a shoot-through condition, a protection circuit that uses TLC372 is designed in accordance with Figure 5-4. This TLC372 consists of two independent voltage comparators [44], each of which is designed to operate from a single power supply (3 V to $16 \mathrm{~V}$ range). The voltage across the voltage divider circuit is compared with the signals from OPA320. The diode LED is designed to light up during the overload condition. The outputs are open-drain configurations and can be connected to achieve positive-logic wired-AND relationships. 


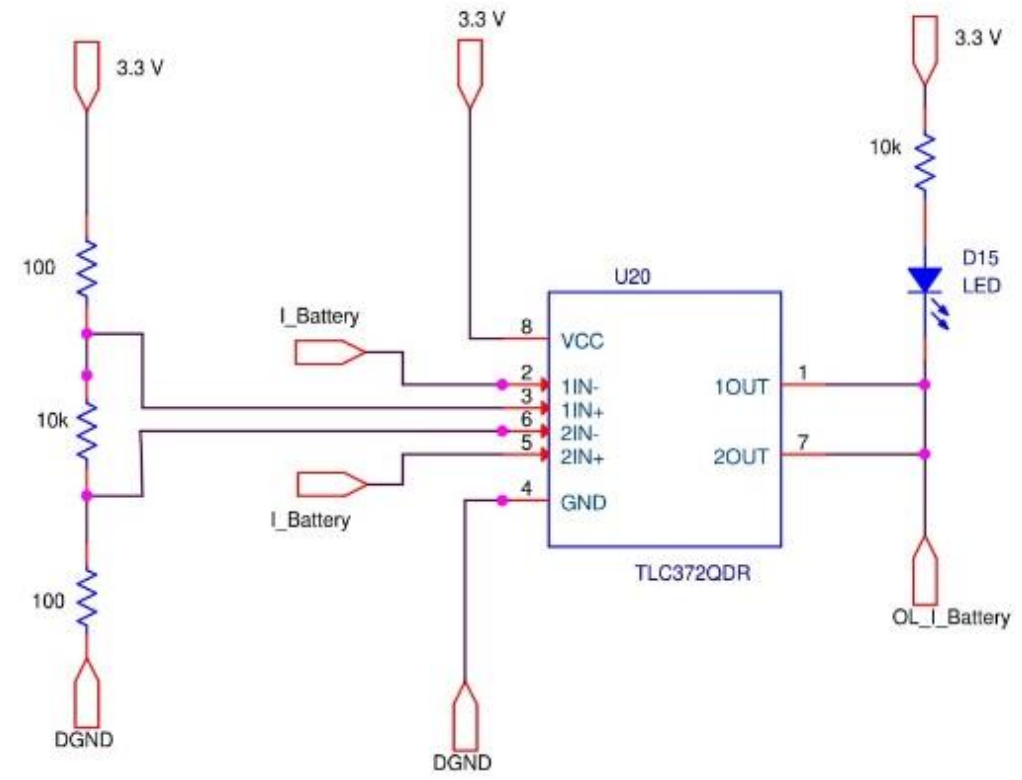

Figure 5-4 Schematics of overload protection circuit.

Besides the aforementioned components, others include the connectors to link different sub-modules and battery cells, test points to test the voltage, and current sensor outputs. The designed board contains four layers to increase the spacing between high switching-frequency components, such as MOSFETs and printed circuit board (PCB) traces. 


\section{CHAPTER 6. CONCLUSION AND FUTURE WORK}

\subsection{Conclusion}

This thesis has proposed a one-step-horizon MPC scheme for a three-phase IPMM that is fed by MMC modules. The main findings of this work are presented as follows with their corresponding conclusions:

1) Simulation results in chapter 5 show that the tracking performance of MPC is directly dependent on the sampling frequency of the controller. Faster controller sampling frequency leads to better reference tracking and vice-versa. However, for performing calculation-intensive MPC optimizations in small sample time, powerful DSPs are needed. A larger number of sub-modules are included in MMC to overcome this challenge. The reference tracking error decreases with the increase in number of sub-modules. Thus, to compensate for the low sampling frequency of the DSP, the number of sub-modules is increased in the MMC.

2) To attain the required harmonic content in the output current, the MMC with a lower number of sub-modules switches at higher voltage and frequency compared to the MMC with a higher number of sub-modules. Reduction in harmonics is due to the availability of more voltage levels in the latter. Because of switching at a higher voltage and a higher frequency, the MMC with a lower number of sub-modules have greater switching losses.

3) The implemented cost function in MPC is adaptive and changes according to the current tracking error. It can reduce the phase voltage ripple, relieve the microcontroller of extra calculation burden, decrease the switching frequency, and 
ensure the motor work under safe current limits by including the system constraints. The current tracking performance is further improved by fine-tuning the weights of the constraints.

4) Simulation results demonstrate that the proposed control scheme can track the reference speed by operating in MTPA, FW and MTPV regions for maximum efficiency.

5) The modular nature of MMC allows the control of individual battery cells in each sub-module. An algorithm is designed to ensure that the terminal voltage levels of all battery cells in the MMC system are equalized within the driving cycle.

\subsection{Future Work}

Due to time constraints, other adaptations, tests, and experiments must be left to further investigations. This future research should concern a deeper analysis of particular mechanisms and new methods regarding the following ideas.

1. Adding ultracapacitors to provide instantaneous power: Li-Ion cells have high energy density but lower power density compared to ultracapacitors. During the starting of the motor, high starting torque demands high initial current, which imposes intense stress on battery cells. Conventional ultracapacitors have the advantage of delivering fast bursts of power and can be recharged thousands of times without losing much capacity.

2. Include regenerative braking to recover the energy: In this thesis, an EV can use regenerative braking to recoup energy during braking, which is not possible for conventional ICE vehicles. Regenerative braking is the process of feeding energy from the drive motor back into the battery during the braking process, when the vehicle's 
inertia forces the motor into generator mode. With the H-bridge topology of the proposed MMC converter, the direction of the flow of current can be controlled, and regenerative braking and charging of battery cells can hence be achieved in the proposed control structure.

3. Increasing the horizon of MPC: The mechanical systems have a significantly low time constant compared to electrical systems; thus it is possible to predict the future states of the motor for a larger prediction horizon. The present thesis focuses on MPC with a unit step horizon. However, increasing the prediction horizon should further enhance the reference tracking performance.

4. Prediction of weights by machine learning: In the proposed control scheme, the weights of the cost function are determined by the hit-and-trial method. However, a machine-learning technique can predict the weights based on the state of the motor operation. Such accurate variation of weights is expected to boost the tracking performance of the motor.

While all of the aforementioned points will improve the performance of the systems, addition of an ultracapacitor would improve the system's performance many folds. Combining the high-power density of ultracapacitor with the high energy density of batteries can improve the performance of the EV motor, as the ultracapacitor can provide high starting torques, and batteries can take over during steady-state operation. This approach would decrease the high stress on battery cells due to a sudden rise in current and would thus improve the battery life. 
Preliminary work on the design of MMC submodule has already begun: Figure 6-1 offers the topology for this work. The cost function for the topology in this figure would include capacitor charge and power required by the load besides the error and constraint terms as discussed in this thesis.

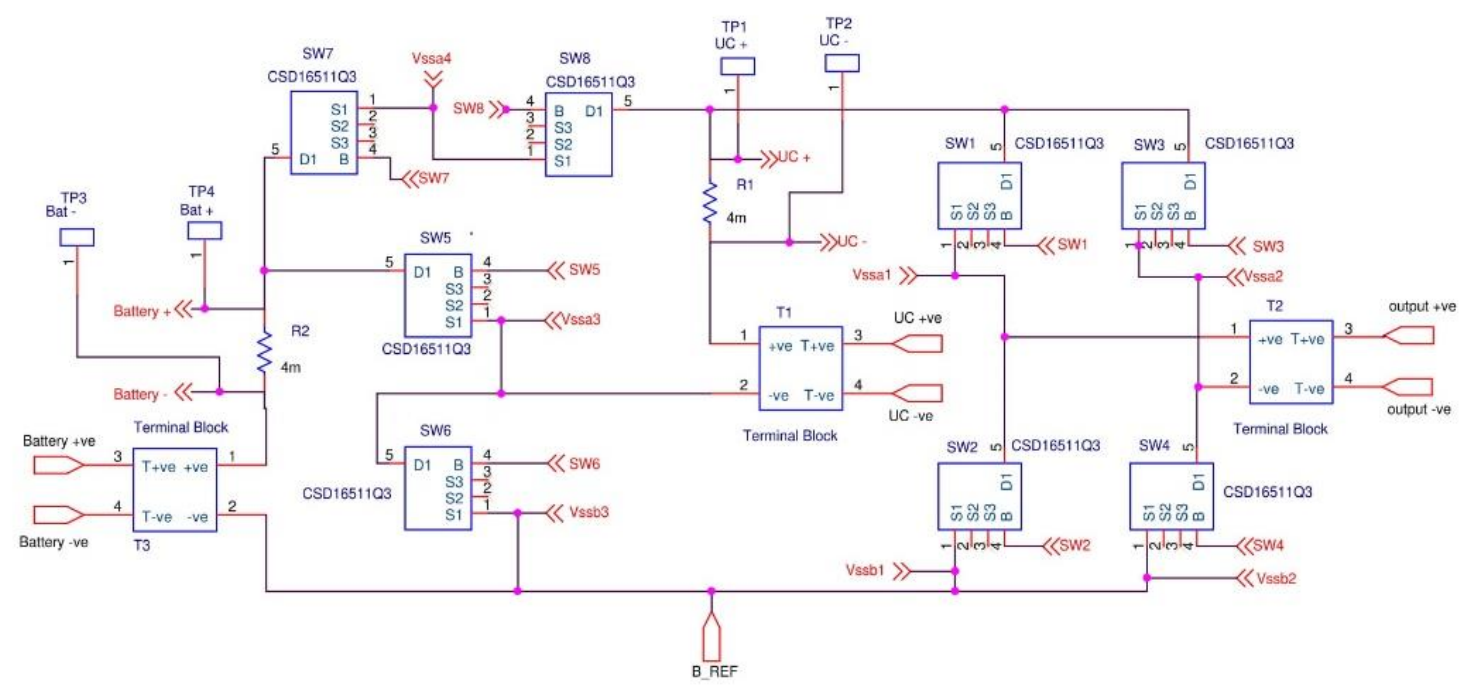

Figure 6-1 Schematics of new sub-module topology. 


\section{REFERENCES}

[1] "How Clean is Your Electric Vehicle?," Union of Concerned Scientists. [Online]. Available: https://www.ucsusa.org/clean-vehicles/electric-vehicles/ev-emissionstool. [Accessed: 27-Oct-2018].

[2] K. Palmer, J. E. Tate, Z. Wadud, and J. Nellthorp, "Total cost of ownership and market share for hybrid and electric vehicles in the UK, US and Japan," Appl. Energy, vol. 209, pp. 108-119, Jan. 2018.

[3] G. X. ETFs, "The Future Of Transportation Is Autonomous And Electric," Seeking Alpha, 17-Apr-2018. [Online]. Available: https://seekingalpha.com/article/4163546future-transportation-autonomous-electric. [Accessed: 27-Oct-2018]

[4] "Electrifying insights: How automakers can drive electrified vehicle sales and profitability McKinsey." Internet: https://www.mckinsey.com/industries/automotiveand-assembly/our-insights/electrifying-insights-how-automakers-can-driveelectrified-vehicle-sales-and-profitability. [Accessed: 27-Oct-2018].

[5] A. Bălţăţanu and M. Florea, "Comparison of electric motors used for electric vehicles propulsion," International Conference of Scientific Paper, Afases 2013, Brasov, 2325 May 2013.

[6] W. L. Soong and N. Ertugrul, "Field-weakening performance of interior permanentmagnet motors," in IEEE Transactions on Industry Applications, vol. 38, no. 5, pp. 1251-1258, Sept.-Oct. 2002

[7] I. Takahashi and T. Noguchi, "A New Quick-Response and High-Efficiency Control Strategy of an Induction Motor," IEEE Trans. Ind. Appl., vol. IA-22, no. 5, pp. 820827, Sep. 1986.

[8] W. Jun, P. Hong, and J. Yu, "A simple direct-torque fuzzy control of permanent magnet synchronous motor driver," in Intelligent Control and Automation, 2004. WCICA 2004. Fifth World Congress on, 2004, vol. 5, pp. 4554-4557.

[9] K. M. Tsang and W. L. Chan, "Adaptive control of power factor correction converter using nonlinear system identification," IEE Proc.-Electr. Power Appl., vol. 152, no. 3, pp. 627-633, 2005.

[10] J. Holtz, "A predictive controller for the stator current vector of ac machines fed from a switched voltage source," Proc IEE Jpn. IPEC-Tokyo83, pp. 1665-1675, 1983.

[11] P. Cortés, M. P. Kazmierkowski, R. Kennel, D. E. Quevedo, and J. R. Rodriguez, "Predictive Control in Power Electronics and Drives.," IEEE Trans Ind. Electron., vol. 55, no. 12, pp. 4312-4324, 2008. 
[12] M. H. Moradi, "Predictive control with constraints, J.M. Maciejowski; Pearson Education Limited, Prentice Hall, London, 2002, pp. IX+331, price £35.99, ISBN 0201-39823-0," Int. J. Adapt. Control Signal Process., vol. 17, no. 3, pp. 261-262, Apr. 2003.

[13] S. Bolognani, S. Bolognani, L. Peretti, and M. Zigliotto, "Design and Implementation of Model Predictive Control for Electrical Motor Drives," IEEE Trans. Ind. Electron., vol. 56, no. 6, pp. 1925-1936, Jun. 2009.

[14] "Long-range predictive control of current regulated PWM for induction motor drives using the synchronous reference frame - IEEE Journals \& Magazine." [Online]. Available: https://xploresit.ieee.org/document/553670. [Accessed: 22-Oct2018].

[15] E. S. de Santana, E. Bim, and W. C. do Amaral, "A Predictive Algorithm for Controlling Speed and Rotor Flux of Induction Motor," IEEE Trans. Ind. Electron., vol. 55 , no. 12 , pp. 4398-4407, Dec. 2008.

[16] A. Linder and R. Kennel, "Model Predictive Control for Electrical Drives," 2005, vol. 2005, pp. 1793-1799.

[17] M. Preindl and S. Bolognani, "Model Predictive Direct Torque Control With Finite Control Set for PMSM Drive Systems, Part 1: Maximum Torque Per Ampere Operation," IEEE Trans. Ind. Inform., vol. 9, no. 4, pp. 1912-1921, Nov. 2013.

[18] M. Preindl and S. Bolognani, "Model Predictive Direct Torque Control With Finite Control Set for PMSM Drive Systems, Part 2: Field Weakening Operation," IEEE Trans. Ind. Inform., vol. 9, no. 2, pp. 648-657, May 2013.

[19] J. Rodriguez, Jih-Sheng Lai, and Fang Zheng Peng, "Multilevel inverters: a survey of topologies, controls, and applications," IEEE Trans. Ind. Electron., vol. 49, no. 4, pp. 724-738, Aug. 2002.

[20] M. Malinowski, "Cascaded multilevel converters in recent research and applications,” Bull. Pol. Acad. Sci. Tech. Sci., vol. Vol. 65, no. nr 5, 2017.

[21] P. V. Kapoor and M. M. Renge, "Improved Performance of Modular Multilevel Converter for Induction Motor Drive," Energy Procedia, vol. 117, pp. 361-368, Jun. 2017.

[22] K. Sharifabadi, L. Harnefors, H.-P. Nee, S. Norrga, and R. Teodorescu, Design, Control, and Application of Modular Multilevel Converters for HVDC Transmission Systems. John Wiley \& Sons, 2016. 
[23] V. Najmi, "Modeling, Control and Design Considerations for Modular Multilevel Converters," Masters of science thesis, Virginia Polytechnic Institute and State University, USA, 2015.

[24] "A New Configuration of Multilevel Inverter with Lower Number of Circuit Elements," ResearchGate. Internet: https://www.researchgate.net/publication/321443827_A_New_Configuration_of_M ultilevel_Inverter_with_Lower_Number_of_Circuit_Elements. [Accessed: 22-Oct2018].

[25] J. M. Kharade and D. N. G. Savagave, "A Review of HVDC Converter Topologies," International Journal of Innovative Research in Science, Engineering and Technology, vol. 6, no. 2, p. 9, 2007.

[26] J. B. Rawlings and D. Q. Mayne, "Postface to 'Model Predictive Control: Theory and Design," " p. 726.

[27] S. M. Goetz, A. V. Peterchev, and T. Weyh, "Modular Multilevel Converter With Series and Parallel Module Connectivity: Topology and Control," IEEE Trans. Power Electron., vol. 30, no. 1, pp. 203-215, Jan. 2015.

[28] J. Kim, J. Shin, C. Chun, and B. H. Cho, "Stable Configuration of a Li-Ion Series Battery Pack Based on a Screening Process for Improved Voltage/SOC Balancing," IEEE Trans. Power Electron., vol. 27, pp. 411-424.

[29] M. Kokila, P. Manimekalai, and V. Indragandhi, "Design and development of battery management system (BMS) using hybrid multilevel converter," Int. J. Ambient Energy, vol. 0, no. 0, pp. 1-9, Jun. 2018

[30] Zheng, Z., Wang, K., Xu, L., \& Li, Y. (2014). A hybrid cascaded multilevel converter for battery energy management applied in electric vehicles. IEEE Transactions on power electronics, 29(7), 3537-3546.

[31] C. French and P. Acarnley, "Direct torque control of permanent magnet drives," IEEE Transactions on Industry Applications, vol. 32, no. 5, pp. 1080-1088, September/October 1996

[32] M. O. Badawy, et. al., "Integrated Control of an IPM Motor Drive and a Novel Hybrid Energy Storage System for Electric Vehicles", in IEEE Trans. Ind. Appl., 2017, vol. 53, pp. 5810-5819. 
[33] Xuecong Xu, et. al., "Predictive speed control of interior permanent magnet synchronous motor with maximum torque per ampere control strategy," in 36th Chinese Control Conference, Dalian, China, Jul. 2017

[34] Leopold Sepulchre, et. al., "New High Speed PMSM Flux-Weakening Strategy", 19th International Conference on Electrical Machines and Systems, Chiba, Japan, Nov. 13-16, 2016

[35] Pavel Vaclavek and Petr Blaha "Interior Permanent Magnet Synchronous Machine High Speed Operation using Field Weakening Control Strategy", 12th WSEAS Conference on SYSTEMS, Heraklion, Greece, July 22-24 2008

[36] R. N. Fard, "Finite Control Set Model Predictive Control in Power Converters," p. 87.

[37] E. J. Fuentes, J. Rodriguez, C. Silva, S. Diaz and D. E. Quevedo, "Speed control of a permanent magnet synchronous motor using predictive current control," 2009 IEEE 6th International Power Electronics and Motion Control Conference, Wuhan, 2009, pp. 390-395.

[38] Y. Xiong, S. Sun, H. Jia, P. Shea and Z. John Shen, "New Physical Insights on Power MOSFET Switching Losses," in IEEE Transactions on Power Electronics, vol. 24, no. 2, pp. 525-531, Feb. 2009

[39] Texas Instruments, "25-V N-Channel NexFET Power MOSFET,” CSD16411Q3 datasheet, August 2009 [Revised Nov. 2016].

[40] Texas Instruments, "A 4-A, 6-A, 5.7-kVRMS Isolated Dual-Channel Gate Driver," UCC21520, UCC21520A datasheet, June 2016 [Revised Dec. 2017].

[41] Texas Instruments, "Dual Buffer Gate," SN74LVC2G34 datasheet, August 2001 [Revised Oct. 2015].

[42] Texas Instruments, "OPAx320x Precision, 20-MHz, 0.9-pA, Low-Noise, RRIO, CMOS Operational Amplifier with Shutdown," OPA320 datasheet, August 2010 [Revised Dec. 2016].

[43] Texas Instruments, "AMC1301 Precision, \pm 250 -mV Input, 3- $\mu$ s Delay, Reinforced Isolated Amplifier," AMC1301 datasheet, April 2016 [Revised March 2018].

[44] Texas Instruments, "LinCMOS dual differential comparators," TLC372 datasheet, Nov. 1983 [Revised July 2008]. 